\title{
ARTICLE
}

\section{Proteomics of yeast telomerase identified Cdc48-Npl4-Ufd1 and Ufd4 as regulators of Est1 and telomere length}

\author{
Kah-Wai Lin ${ }^{1, \star}$, Karin R. McDonald ${ }^{1, \star}$, Amanda J. Guise ${ }^{1}$, Angela Chan ${ }^{1}$, Ileana M. Cristea ${ }^{1}$ \& Virginia A. Zakian ${ }^{1}$
}

\begin{abstract}
Almost 400 genes affect yeast telomere length, including Est1, which is critical for recruitment and activation of telomerase. Here we use mass spectrometry to identify novel telomerase regulators by their co-purification with the telomerase holoenzyme. In addition to all known subunits, over 100 proteins are telomerase associated, including all three subunits of the essential Cdc48-Npl4-Ufd1 complex as well as three E3 ubiquitin ligases. The Cdc48 complex is evolutionarily conserved and targets ubiquitinated proteins for degradation. Est1 levels are $\sim 40$-fold higher in cells with reduced $\mathrm{Cdc} 48$, yet, paradoxically, telomeres are shorter. Furthermore, Est1 is ubiquitinated and its cell cycle-regulated abundance is lost in Cdc48-deficient cells. Deletion of the telomerase-associated E3 ligase, Ufd4, in cdc48-3 cells further increases Est1 abundance but suppresses the telomere length phenotype of the single mutant. These data argue that, in concert with Ufd4, the Cdc48 complex regulates telomerase by controlling the level and activity of Est1.
\end{abstract}

\footnotetext{
${ }^{1}$ Department of Molecular Biology, Lewis Thomas Laboratory, Princeton University, Washington Road, 08544 Princeton, New Jersey, USA.

*These authors contributed equally to this work. Correspondence and requests for materials should be addressed to I.M.C. (email: icristea@princeton.edu) or to V.A.Z. (email: vzakian@princeton.edu).
} 
O wing to the properties of conventional DNA polymerases, the very ends of linear DNA molecules require a special replication mechanism, which in almost all eukaryotes is provided by telomerase, a telomere-dedicated reverse transcriptase. The catalytic core of telomerase consists of the reverse transcriptase (hTERT, humans; Est2, budding yeast) and a templating RNA (hTR, humans; TLC1, budding yeast). In addition, the telomerase holoenzyme contains accessory proteins that are essential for the stability and/or activity of the telomerase holoenzyme in vivo.

Est 1 is the best conserved of the telomerase accessory proteins, present from yeasts to humans. In budding and fission yeasts, Est1 is essential for telomerase-mediated telomere maintenance with roles in both recruitment and activation of telomerase ${ }^{1-3}$. The Saccharomyces cerevisiae telomerase accessory protein Est3 (refs 4,5), which is also essential for in-vivo telomerase activity, is found only in budding yeasts. However, structural predictions suggest that it is similar to the mammalian TPP1 (refs 4,5), a telomere structural protein that increases telomerase processivity ${ }^{6,7}$. In budding yeast, Est3 interacts directly with both Est1 (ref. 8) and Est2 (refs 9,10), and its association with Est1 is required for its recruitment to telomeres in vivo ${ }^{8}$.

Telomerase activity is tightly regulated. Part of this regulation is at the level of abundance, as telomerase is either absent (most human somatic cells) ${ }^{11}$ or present in very low amounts, fewer than one complex per telomere (budding and fission yeasts) ${ }^{1,12,13}$. Even in human stem cells that express telomerase, its activity is low, as heterozygous mutations that reduce the abundance of a telomerase component or telomere structural protein can cause premature death as a result of stem cell failure (reviewed in refs 14,15). Likewise, telomerase RNA is haplo-insufficient for maintenance of telomere length in both budding ${ }^{13}$ and fission yeasts, as is the fission yeast Estl (Webb and Zakian, in preparation). Telomerase is upregulated in $\sim 85 \%$ of human tumours $^{15}$ and its expression promotes tumorigenesis ${ }^{16}$. Thus, understanding telomerase regulation is relevant to ageing and cancer.

In budding and fission yeast, telomerase action is cell cycle regulated, occurring only in late $\mathrm{S} / \mathrm{G} 2$ phase $\mathrm{e}^{17,18}$. In budding yeast, part of this regulation is due to the cell cycle-regulated expression of Est1, which is low in G1 phase $(\sim 20$ molecules per cell) and high at the end of the cell cycle $(\sim 110$ molecules per cell) when telomerase is active ${ }^{1,19}$. Although Est1 is the only core subunit of $S$. cerevisiae telomerase whose abundance is cell cycle regulated, given that it is required to recruit Est3 into the holoenzyme and to telomeres, ${ }^{8}$, Est3 action is also cell cycle regulated. Although Est1 regulation is not sufficient to restrict telomerase to a short window of the cell cycle ${ }^{20}$, its biology is key for understanding cell cycle regulation of telomerase.

In budding and fission yeasts, genetics has been extremely successful at identifying a large number of genes whose mutation affects telomere length (reviewed in refs 21,22). However, for most of these genes, it is not known whether they affect telomeres directly. We reasoned that mass spectrometry (MS) analysis of telomerase might identify proteins with direct effects on telomerase. Indeed, MS has been extremely useful for identifying novel telomerase components and regulators from both ciliates ${ }^{23-25}$ and human cultured cells ${ }^{26-28}$. However, the very low abundance of yeast telomerase has hampered attempts to use MS, to identify proteins that co-purify with telomerase.

We describe methods to purify active telomerase from budding yeast and to identify interacting proteins by MS. This approach identified multiple candidates for novel telomerase regulatory proteins, including the three subunits of a Cdc48 complex, Cdc48, Npl4 and Ufd1. Cdc48, an AAA ATPase, is an evolutionarily conserved protein that is the catalytic subunit of several multi-protein complexes that contain ubiquitin receptors, such as Npl4 and Ufd1 (reviewed in ref. 29). These complexes act as segregases that recognize and remove ubiquitinated proteins from multi-protein complexes ${ }^{30-32}$. From yeasts to humans, Cdc48 complexes are implicated in a plethora of diverse nuclear and cytoplasmic processes, including cell cycle progression, membrane fusion, repair of double-strand breaks, termination of DNA replication, modification of transcription factors, postmitotic reassembly of the nuclear envelope and export of proteins from the endoplasmic reticulum and mitochondria (reviewed in ref. 33). However, Cdc48 has not been linked previously to telomerase. The diverse phenotypes associated with loss of Cdc48 are mostly due to its role in promoting proteasomemediated degradation, where it acts at a step after ubiquitination and before degradation of target proteins ${ }^{34,35}$. Mutations of its human homologue, p97 or VCP (valosin-containing protein), cause a dominant multi-organ and progressive degenerative syndrome of the muscles, bone and brain, called VCP disease ${ }^{36}$.

Here we report a previously unrecognized mechanism of telomerase regulation in which the Cdc48-Npl4-Ufd1 complex affects Est1 abundance, activity and cell cycle regulation, as well as telomere length. Moreover, deletion of a telomerase-associated E3 ubiquitin ligase (E3 Ub), Ufd4, which has also not been linked previously to telomeres, results in long telomeres, while its deletion from $c d c 48-3$ cells suppresses the short telomere length phenotype of $c d c 48-3$ cells. These data suggest that Ufd4 ubiquitinates Estl and this modified Est1 is removed from the holoenzyme by the Cdc48 complex. As the Cdc48 complex and Est1 are both highly conserved, these data may be relevant to telomerase regulation in humans.

\section{Results}

Generation of a telomerase-overexpressing strain. The low abundance of $S$. cerevisiae telomerase has thwarted previous attempts to study it by MS. To circumvent this problem, we generated a strain that overexpressed (OE) each of the four essential telomerase subunits: TLC1 RNA, Est1, Est2 and Est3 (hereafter OE strain). The chromosomal copy of the gene for each component was put under the control of the strong and inducible GAL1 promoter. To aid in immunopurification of the holoenzyme, Est1 and Est2 were expressed as green fluorescent protein (GFP) fusions (Fig. 1a). A strain with a GAL1-regulated nuclearlocalized GFP was used as a specificity control as it allowed elimination of proteins with nonspecific associations to the resin or GFP tag (Fig. 1a, Control). The telomerase OE strain had normal viability, growth rate and cell cycle progression (Fig. 1b).

Western blot analysis using an anti-GFP antibody readily detected Est1 and Est2 in the OE strain (Fig. 1c and Supplementary Fig. 1A). However, the level of overexpression of these proteins could not be determined, because neither Est1GFP nor Est2-GFP expressed from its endogenous promoter was detectable by western blotting (Fig. 1c and Supplementary Fig. 1C). Therefore, we used the abundance of TLC1 RNA in wild-type (WT) versus telomerase OE strain to estimate the extent of overexpression (Fig. 1d and Supplementary Fig. 1D). Northern analysis indicated approximately ten times more telomerase RNA in the OE strain than in WT cells (Fig. 1d and Supplementary Fig. 1D). As TLC1 is the subunit present in the lowest number per cell, this value is a good approximation of the maximum level of holoenzyme overexpression ${ }^{1,8,13}$.

To determine whether the OE telomerase was active, we used Southern analysis to determine telomere length in two independent isolates of the OE strain (Fig. 1e). Telomeres in the two OE isolates progressively lengthened over four successive restreaks. By restreak four, telomeres were $\sim 80-130$ bp longer than the 
a

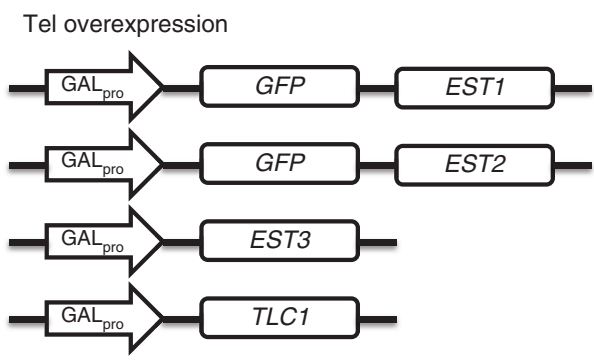

Control

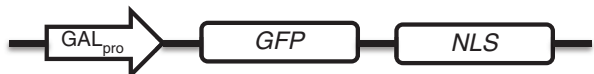

C

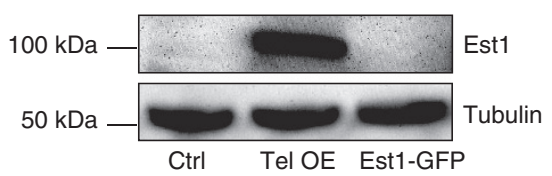

d

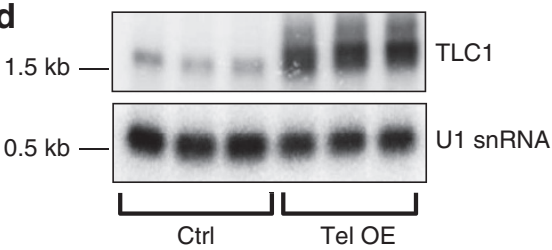

e b Control

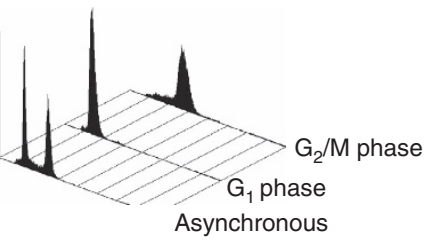

Telomerase overexpression

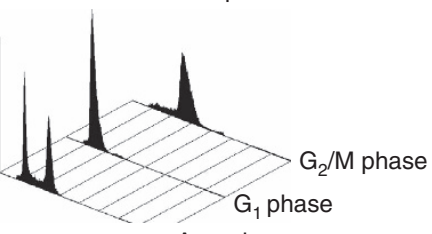

Asynchronous

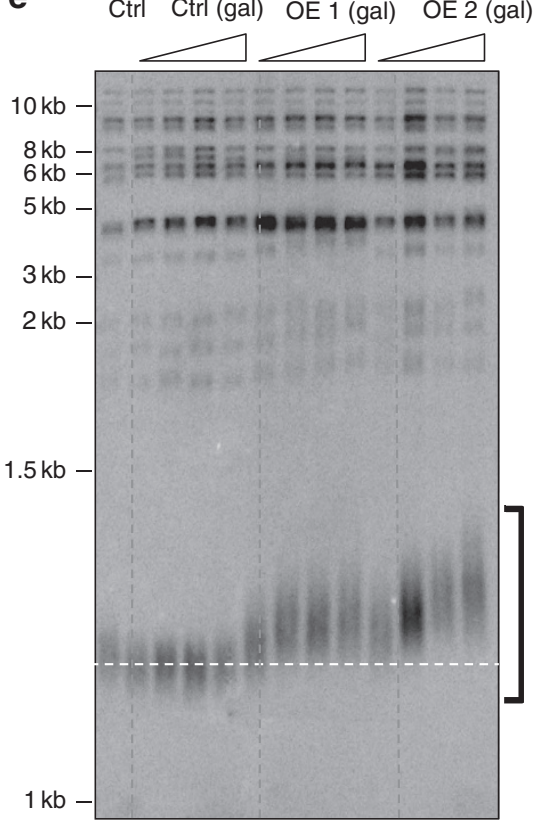

Figure 1 | Generation and characterization of strains for purification of telomerase. (a) In the telomerase OE strain, each of the four essential telomerase subunits, Est1, Est2, Est3 and TLC1 RNA, was expressed from the galactose-inducible GAL1 promoter as the only form of the gene product in the strain. Est1 and Est2 were expressed as GFP fusions. The control for the telomerase OE strain contained a fusion gene, GALT-GFP-NLS in which the nuclear localization signal (NLS) from the SV4O T-antigen was fused to GFP. (b) FACS analyses of both the control (top) and telomerase OE strains (bottom) as asynchronous cultures or arrested in G1 or G2/M phase by $\alpha$-factor and nocodazole, respectively. (c) Western blot analysis using an anti-GFP antibody readily detected Est1 in galactose-grown telomerase OE cells but not in galactose-grown control strain (Ctrl) nor from glucose-grown cells expressing Est1-GFP from the EST1 promoter. The full lane view of this blot is shown in Supplementary Fig. 1C. (d) Northern blot analysis was carried out on three isolates from both the control and telomerase OE strain growing in galactose media. The northern blot was probed for TLC1 RNA and for U1 snRNA. Quantification by ImageQuant TL (GE Healthcare) indicated that there was 10-12 times more TLC1 RNA in the telomerase OE cells compared with the control. The full lane view of this blot is shown in Supplementary Fig. 1D. (e) OE of telomerase results in telomere lengthening. Southern analysis of telomere length in two independent isolates of telomerase OE cells (OE1 and OE2) growing in galactose for four successive re-streaks compared with control cells grown in the same way (Ctrl(gal)). Lane labelled Ctrl is from glucose-grown control cells. DNA was digested with Xhol. The blot was probed with pCT300, which detects TG ${ }_{1-3}$ telomeric repeats. Size markers are in kbp. Bracket indicates terminal restriction fragments from $\mathrm{Y}^{\prime}$-bearing telomeres. Here and in subsequent figures, horizontal dashed line marks mean telomere length in control cells.

$\sim 300 \mathrm{bp}$ in the galactose grown control. Thus, the OE telomerase is active.

Proteomic profiling of purified telomerase. GFP-tagged telomerase components Est1 and Est2 were immuno-affinity purified using high-titre polyclonal rabbit anti-GFP antibodies and extraction conditions that optimized telomerase recovery ${ }^{37}$. As telomerase activity is regulated during the cell cycle, telomerase was purified from cells arrested in either late G1 phase by treatment with $\alpha$-factor (telomerase inactive) or in G2/M phase by treatment with nocodazole (telomerase active) (Fig. 1b and Supplementary Fig. 1A) ${ }^{17,18}$. Lysates were treated (or not) with DNase I to distinguish proteins with DNA-dependent associations and resolved by SDS-polyacrylamide gel electrophoresis (SDS-PAGE) before MS analysis (Supplementary Fig. 1B).

To determine the specificity of individual protein interactions, we used the SAINT (Significance Analysis of INTeractome) algorithm to calculate specificity scores by comparing proteins 
that co-isolated with telomerase to GFP controls ${ }^{38}$. The SAINT algorithm employs a probabilistic scoring method incorporating the number of spectra detected in both experimental and control isolations, frequency of detection across biological replicates and protein length. We adopted a stringent SAINT score cutoff of 0.8 , which retained only the most prominent interactions (top $\sim 5 \%$, Supplementary Data 1). Using these criteria, a combined total of 115 proteins were identified in the $\mathrm{G} 1$ and $\mathrm{G} 2 / \mathrm{M}$ isolations (89 with G1 phase telomerase and 72 with G2/M phase telomerase; Supplementary Data 1 ). Of these, $32 \%$ were telomerase associated after DNase I treatment (37 proteins in both G1 and in G2/M phases; these proteins are in bold and italics in Supplementary Data 1).

Isolation method identified all known telomerase subunits. As expected, given the isolation strategy, GFP-tagged Est1 and Est2 were both identified with high confidence from immuno-isolates, as demonstrated by very high sequence coverage (Est1: 78\%; Est2: $70 \%$ ) and high spectral counts (Supplementary Data 1). Likewise, the other essential telomerase protein, Est3, which was not GFP tagged, was present with high confidence in the immuno-isolates (Supplementary Data 1). TLC1 RNA has an Sm protein-binding site near the $3^{\prime}$-end of the molecule, whose mutation leads to reduced TLC1 levels and short telomeres, and two of the seven Sm proteins, Smd1 and Smd3, bind TLC1 RNA in vivo ${ }^{39}$. All seven Sm proteins (Smd1, Smd2, Smd3, Smb1, Sme1, Smx2 and Smx3) were identified with high specificity scores; Sme1 was the only one that was not present in both G1 and G2/M phase telomerase. With the exception of Smx2 and Smx3, all of these associations were DNase I resistant (Supplementary Data 1). In addition, 32 of the G1 and G2/M telomerase-associated proteins had been linked previously to telomere length or telomerase regulation (Supplementary Data 1). Thus, all known telomerase subunits and 22 proteins with reported links to telomere biology were present in the immuno-isolates, representing $\sim 30 \%$ of the 115 proteins identified. However, the majority of the associated proteins that co-purified with Est1/Est2 had not been linked previously to telomerase and are candidates for new telomerase regulators.

Analysis of the telomerase interactome. We used information from STRING- $\mathrm{db}^{40}$ and Cytoscape ${ }^{41}$, to generate a functional protein interaction network (Fig. 2a). Proteins were clustered into functional protein complexes and groupings using Saccharomyces Genome Database (SGD) annotations and STRING connectivity (Table 1 and Fig. 2a).

Multiple proteins involved in proteolysis were detected in both G1 and G2/M telomerase, although they were often enriched in G1 isolations (Table 1). This subset includes Cdc48, Npl4 and Ufd1, which act in a complex to target ubiquitinated proteins for proteosomal degradation (Fig. 2a and Supplementary Fig. 2). The Cdc48 cofactor Shp1 was also more abundant in G1 phase telomerase isolations, as were 22 of the 32 subunits of the proteasome (Fig. 2a and Table 1). Three E3 Ub ligases, Tom1, Ubr1 and Ufd4, as well as the deubiquitinase, Ubp15, were also telomerase associated with increased interaction abundance in G1 phase (Fig. 2a and Table 1).

In addition to the $\mathrm{Cdc} 48$ and proteasome complexes, other multi-subunit complexes were telomerase associated. For example, Pop1, Pop6 and Pop7 are components of both RNase MRP and nuclear RNase P. Both complexes are involved in RNA processing 42 .

Among the most prominent associations with known telomere functions were Yku70 and Yku80, which form a heterodimer that binds telomeres and telomerase RNA (reviewed in ref. 21). However, the association of both proteins was DNase sensitive
(Fig. 2a, hexagon-shaped nodes), suggesting that the Yku70/80 complex is not part of the holoenzyme. Similarly, the telomerase association of Hsp82, a protein implicated in regulating the DNAbinding activity of Cdc13 (ref. 43), was DNase sensitive.

Using the DAVID Bioinformatics Database ${ }^{44}$, we determined whether specific functional classes were more highly represented in the telomerase isolations than in the yeast genome as a whole. This functional annotation demonstrated significant $(P<0.05$, modified Fisher's exact test (EASE) ${ }^{44}$ ) enrichment of proteins in telomere maintenance/assembly, RNA splicing, RNA $3^{\prime}$-end processing/catabolism, messenger RNA processing/catabolism, proteolysis, ubiquitin-dependent processes and small nucleolar RNA processing (Fig. 2b).

The Cdc48 complex affects telomere length. To determine whether novel telomerase-associated protein had effects on telomere maintenance, we started with the Cdc48 complex as all three of its subunits, Cdc48, Npl4 and Ufd1, were among the most prominent telomerase-associated proteins with SAINT scores of 1 in both G1 and G2/M phase, and the association of each subunit was DNase resistant. In addition, the recovered peptides had high amino acid sequence coverage (an average of $76 \%$ for Cdc $48,36 \%$ for $\mathrm{Npl} 4$ and $37 \%$ for Ufd1).

If the association of the $\mathrm{Cdc} 48$ complex with telomerase is functionally important, we expect its loss to affect telomere length. As each of the three subunits is essential, we examined telomere length as well as other phenotypes in strains with temperature-sensitive alleles, $c d c 48-3, n p l 4-1$ and $u f d 1-2$ (ref. 45). Each of these strains arrests at mitosis when grown at $37^{\circ} \mathrm{C}$, the restrictive temperature for all three alleles. Although $c d c 48-3$ cells are viable at $25^{\circ} \mathrm{C}$ (permissive temperature) and $30^{\circ} \mathrm{C}$ (semipermissive temperatures), proteolytic defects of are evident at both temperatures ${ }^{45}$.

DNA prepared from the mutant strains grown at both $25^{\circ}$ and $30^{\circ} \mathrm{C}$ was digested with restriction enzymes and subjected to Southern blot analysis using a probe for telomeric DNA (Fig. 3a). Telomeres in $c d c 48-3$ cells were about $40 \mathrm{bp}$ shorter than an otherwise isogenic WT strain at both $25^{\circ} \mathrm{C}$ and $30^{\circ} \mathrm{C}$. This short telomere phenotype was rescued by introducing a centromere plasmid containing CDC48 (pRS316-CDC48 (ref. 46 and Fig. 3b). Similarly, a $c d c 48-3$ telomerase OE strain had shorter telomeres than WT cells at both $25^{\circ} \mathrm{C}$ and $30^{\circ} \mathrm{C}$ (Fig. 3c). Thus, the effects of the $c d c 48-3$ mutation on telomere length cannot be rescued by overexpression of telomerase. In addition, npl4-1 cells had telomeres that were modestly shorter than the WT isogenic control at both $25^{\circ} \mathrm{C}$ and $30^{\circ} \mathrm{C}$, whereas ufd1-2 cells had WT length telomeres (Fig. 3a). We focused additional experiments on $c d c 48-3$ cells as this mutant had the largest effect on telomere length.

Telomeric silencing is modestly reduced in $c d c 48-3$ cells. To provide more evidence for an effect of the Cdc48 complex on telomeres, we examined the level of telomere position effect (TPE) in mutant versus WT cells. TPE refers to the reversible repression of telomeric gene transcription ${ }^{47}$. In otherwise isogenic strains, cells with long telomeres have more TPE than cells with short telomeres. To monitor TPE, we integrated the URA3 gene adjacent to the left telomere of chromosome VII. Silencing of $U R A 3$ allows growth in the presence of 5-fluoroorotic acid (5-FOA). Consistent with the telomere length data, $c d c 48-3$ cells had $\sim 5 \times$ lower TPE than WT cells, whereas TPE levels in npl4-1 and ufd1-2 cells were the same as WT (Supplementary Fig. 3IA,B,C). TPE was also lower in $c d c 48-3$ cells that overexpress telomerase (Supplementary Fig. 3IIA). The TPE data provide additional support for a telomeric role for the Cdc48 complex. 
a
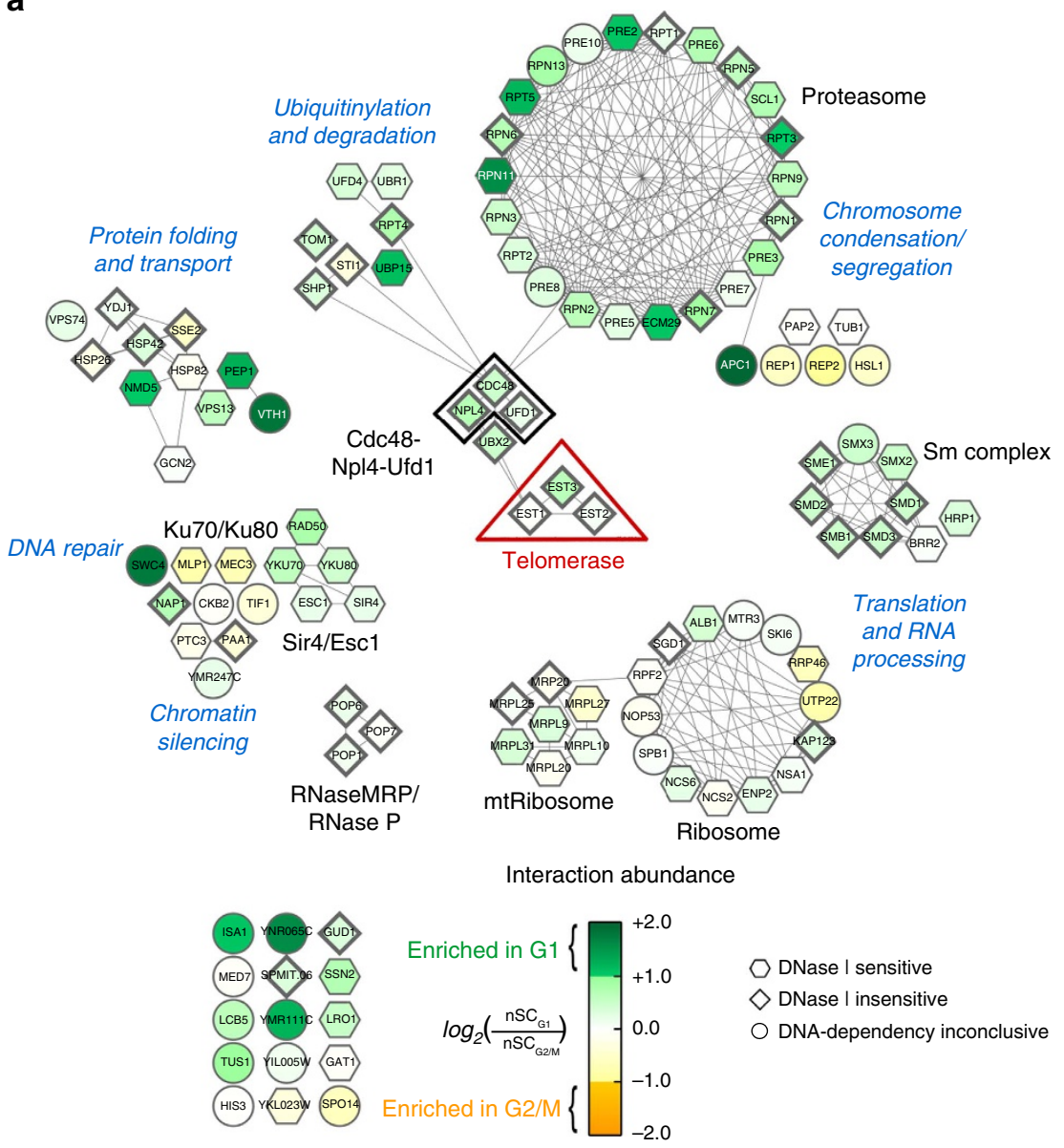

b

EST1/EST2 interactome

(Functions enriched in telomerase interactome)

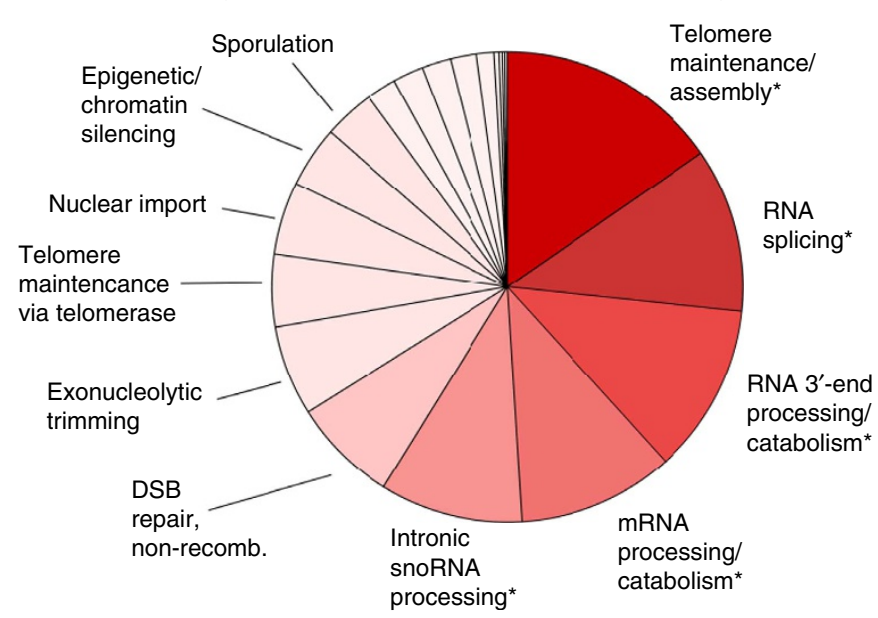

Figure 2 | Functional protein interaction network of telomerase. (a) Cell cycle-dependent changes in protein associations of Est1/Est2. Node colours indicate relative changes in abundance of associations of individual proteins with telomerase during $\mathrm{G} 1$ or $\mathrm{G} 2 / \mathrm{M}$ isolation, as determined by label-free normalized spectrum count comparison (green: enriched in G1; orange, enriched in G2/M). Prominent biological functions are represented in the network. Node shapes indicate the dependence of individual interactions on DNA (hexagons, DNA-dependent; diamonds, DNA-independent; circles, DNA-dependency inconclusive). Edges indicate functional connections among nodes curated by the STRING database. Surprisingly, Est3 was more abundant in $\mathrm{G} 1$ than in G2/M phase telomerase. (b) Gene Ontology enrichment analysis for high specificity (SAINT $\geq 0.8$ ) telomerase interactions present in G1 and G2/M. Functional enrichment comparisons were performed against a whole S. cerevisiae genome background gene list; wedge sizes represent relative DAVID group-enrichment scores $(\min =0.03 / \max =2.63) ;{ }^{\star}$ and bold represents significantly enriched categories $(P<0.05$, modified Fisher's exact test (EASE) ${ }^{44}$ ); colour grading represents relative enrichment over the background genome. 
Table 1 | Telomerase-specific protein interactions associate dynamically with telomerase during cell cycle progression.

\begin{tabular}{|c|c|c|c|}
\hline \multirow{2}{*}{$\begin{array}{l}\text { EST1/EST2 interactions } \\
\text { Gene }\end{array}$} & \multirow{2}{*}{$\begin{array}{l}\text { G1 vs G2/M } \\
\text { Log2 ratio }\end{array}$} & \multicolumn{2}{|c|}{$\begin{array}{l}\text { SAINT scores } \\
\text { Synch. }\end{array}$} \\
\hline & & G1 & G2/M \\
\hline \multicolumn{4}{|l|}{ Telomerase } \\
\hline EST1 & -0.04 & 1.00 & 1.00 \\
\hline EST2 & 0.10 & 1.00 & 1.00 \\
\hline EST3 & 0.65 & 1.00 & 1.00 \\
\hline \multicolumn{4}{|l|}{ Cdc48-Npl4-Ufd1 } \\
\hline $\mathrm{CDC} 48$ & 0.50 & 1.00 & 1.00 \\
\hline NPL4 & 0.71 & 1.00 & 1.00 \\
\hline UFD1 & 0.20 & 1.00 & 1.00 \\
\hline \multicolumn{4}{|l|}{ Sm complex } \\
\hline SMX3 & 0.90 & 1.00 & 0.94 \\
\hline SMB1 & -0.32 & 1.00 & 1.00 \\
\hline SMD1 & 0.46 & 1.00 & 1.00 \\
\hline SMD3 & 0.26 & 1.00 & 1.00 \\
\hline SMD2 & 0.42 & 1.00 & 0.97 \\
\hline SME1 & 0.41 & 1.00 & 0.67 \\
\hline \multicolumn{4}{|l|}{ Ku70/Ku80 } \\
\hline YKU70 & 0.61 & 1.00 & 1.00 \\
\hline YKU80 & 0.46 & 1.00 & 1.00 \\
\hline \multicolumn{4}{|l|}{ RNase $P$} \\
\hline POP1 & 0.14 & 1.00 & 1.00 \\
\hline POP6 & 0.20 & 1.00 & 1.00 \\
\hline POP7 & -0.06 & 0.99 & 0.99 \\
\hline \multicolumn{4}{|l|}{ Ubiquitinylation } \\
\hline APC1 & 2.02 & 1.00 & 0.24 \\
\hline TOM1 & 0.44 & 1.00 & 1.00 \\
\hline UBP15 & 1.15 & 1.00 & 0.80 \\
\hline UBR1 & 0.27 & 1.00 & 1.00 \\
\hline UBX2 & 0.51 & 1.00 & 1.00 \\
\hline UFD4 & 0.37 & 1.00 & 1.00 \\
\hline RPT4 & 0.78 & 1.00 & 0.97 \\
\hline SHP1 & 0.34 & 1.00 & 1.00 \\
\hline STI1 & -0.32 & 1.00 & 1.00 \\
\hline \multicolumn{4}{|l|}{ Proteasome } \\
\hline ECM29 & 1.05 & 0.98 & 0.87 \\
\hline PRE10 & 0.17 & 0.99 & 0.97 \\
\hline PRE2 & 1.08 & 0.87 & 0.65 \\
\hline PRE3 & 0.80 & 1.00 & 0.94 \\
\hline PRE5 & 0.28 & 1.00 & 1.00 \\
\hline PRE6 & 0.73 & 0.96 & 0.94 \\
\hline PRE7 & 0.14 & 0.89 & 0.93 \\
\hline PRE8 & 0.31 & 0.85 & 0.96 \\
\hline RPN11 & -1.62 & 0.93 & 0.34 \\
\hline RPN13 & 0.87 & 0.96 & 0.56 \\
\hline RPN1 & 0.48 & 1.00 & 1.00 \\
\hline RPN2 & 0.64 & 1.00 & 1.00 \\
\hline RPN3 & 0.49 & 0.93 & 0.88 \\
\hline RPN5 & 0.61 & 1.00 & 0.99 \\
\hline RPN6 & 0.70 & 0.99 & 0.90 \\
\hline RPN7 & 0.91 & 0.93 & 0.76 \\
\hline RPN9 & 0.63 & 0.98 & 0.79 \\
\hline RPT1 & 0.20 & 1.00 & 1.00 \\
\hline RPT2 & 0.34 & 0.99 & 0.98 \\
\hline RPT3 & 1.00 & 1.00 & 0.95 \\
\hline RPT5 & 1.21 & 1.00 & 0.98 \\
\hline SCL1 & 0.74 & 0.99 & 0.97 \\
\hline \multicolumn{4}{|c|}{ DNA repair/chromatin organization } \\
\hline CKB2 & -0.08 & 0.80 & 0.05 \\
\hline $\mathrm{ESC1}$ & 0.22 & 0.48 & 0.84 \\
\hline GCN2 & 0.04 & 0.10 & 0.97 \\
\hline MEC3 & -0.70 & 0.47 & 0.92 \\
\hline MLP1 & -0.79 & 0.00 & 0.80 \\
\hline NAP1 & 0.72 & 1.00 & 1.00 \\
\hline PAA1 & -0.37 & 1.00 & 1.00 \\
\hline PTC3 & -0.18 & 0.95 & 0.99 \\
\hline RAD50 & 0.81 & 0.70 & 0.97 \\
\hline SIR4 & 0.20 & 0.94 & 0.00 \\
\hline SWC4 & 1.79 & 0.91 & 0.03 \\
\hline TIF1 & -0.37 & 0.81 & 0.56 \\
\hline YMR247C & 0.21 & 1.00 & 0.99 \\
\hline
\end{tabular}

Proteins co-isolated with telomerase during G1 and G2/M are grouped into functional categories based on gene ontologies and STRING connectivity. Changes in the abundance of protein associations are indicated as the log-transformed ratios of normalized spectrum counts (log2 ratio) for individual cell cycle stages. Interaction specificity for individual proteins was determined using the SAINT algorithm with a specificity score threshold of SAINT $P>0.80$ for either $\mathrm{G} 1$ or $\mathrm{G} 2 / \mathrm{M}$ isolations.

Cdc48 complex regulates Est1 abundance. Given that the Cdc48 complex promotes proteasome-mediated degradation of its target proteins, we considered that its effects on telomere length and
TPE might reflect altered abundance of one or more telomere proteins. To test this possibility, we used western analysis to determine the levels of five Myc-tagged proteins, Est1, Est2, Cdc13, Yku80 and Pif1, and an untagged protein, Rap1, which was detected using a polyclonal antiserum ${ }^{48}$. Est1 and Est2 are core telomerase subunits, Cdc13 and Yku80 are telomere-binding proteins that affect both telomere structure and recruitment of telomerase, Rapl is a telomere-binding protein that is essential for telomere protection and TPE, and Pif1 is a DNA helicase that removes telomerase from DNA ends (reviewed in ref. 21). We compared the abundance of each protein in WT and $c d c 48$-3 cells grown at both $25^{\circ} \mathrm{C}$ and $30^{\circ} \mathrm{C}$ using $\alpha$-tubulin as a loading control (Fig. 4 and Supplementary Fig. 4).

Western blot analysis revealed that Est2, Cdc13, Yku80, Pif1 and Rap1 were expressed at about the same levels in $c d c 48-3$ and WT cells, while Est1 levels were much higher in $c d c 48-3$ cells (Fig. 4a and Supplementary Fig. 4A). This difference was evident in cdc48-3 cells grown at both $25^{\circ} \mathrm{C}$ and $30^{\circ} \mathrm{C}$ compared with WT cells grown at the same temperatures. To estimate the increase in Est1 levels in $c d c 48-3$ cells, we did western blot analysis on a dilution series of the extract from both WT and mutant cells. As the western signal in the undiluted WT extract was comparable to that in a 40-fold dilution of the $c d c 48-3$ extract, Est1 abundance was about 40 times higher in mutant cells (Fig. 4b and Supplementary Fig. 4B). Likewise, Est1 was more abundant in both $25^{\circ} \mathrm{C}$ - and $30^{\circ} \mathrm{C}$-grown npl4- 1 and ufdl-2 cells compared with WT (Fig. 4c and Supplementary Fig. 4C). In ufd12 cells, the Est 1 increase was more evident at the more restrictive temperature of $30^{\circ} \mathrm{C}$ than at $25^{\circ} \mathrm{C}$. As each mutation affected Est1 levels, the short telomeres in $c d c 48-3$ cells are probably due to reduced Cdc48 complex and the more modest effects of the other mutations probably reflect differences in the strengths of the three conditional alleles.

The Cdc48 complex was identified by MS as co-purifying with the Est1-GFP and Est2-GFP, and western blot analysis showed that Est1 abundance was Cdc48 dependent (Fig. 4a and Supplementary Fig. 4A). If the Cdc48 complex interacts specifically with Est1, Est1 should also be present in a Cdc48 immunoprecipitate. To test this possibility, we immunoprecipitated Cdc48 with a goat anti-Cdc48 polyclonal antiserum (Abgent) in cells expressing Est1-Myc. The low-abundance Est1 was readily detected in anti-Cdc48 immunoprecipitates (Fig. 4d and Supplementary Fig. 4D), confirming the Est1-Cdc48 interaction.

Short $\boldsymbol{c d c 4 8 - 3}$ telomeres are not due to limited Est3. Given the activation function of Estl, a priori one expects telomere lengthening rather than the observed telomere shortening when Est1 is OE, as it was in $c d c 48-3$ cells. To test this possibility, we OE Est1 by placing its transcription under the control of the galactose-inducible GAL1 promoter. As reported previously ${ }^{49}$, overexpression of Est1 in our WT background resulted in telomere lengthening ( $\sim 80 \mathrm{bps})$ (Fig. $3 \mathrm{~d})$. However, telomeres were even shorter in $c d c 48-3$ cells expressing Est1 from the GAL1 promoter than in $c d c 48-3$ cells alone $\left(25^{\circ} \mathrm{C}\right.$; Fig. $\left.3 \mathrm{~d}\right)$. Thus, the positive impact of OE Est1 on telomere length requires the $\mathrm{Cdc} 48$ complex.

Est3 interacts directly with Est1 and requires it for telomere binding ${ }^{8}$. Thus, another possibility for short telomeres in $c d c 48-3$ cells is that the very high levels of Est1 sequester Est3 from telomeres. If this model is correct, overexpression of Est3 in cdc48-3 cells might restore telomeres to a more WT-like length. However, Est3 overexpression had little or no effect on telomere length in $c d c 48-3$ or WT cells (Supplementary Fig. 5), suggesting that telomere shortening in $c d c 48-3$ cells is not a consequence of cells being limited for Est3. 

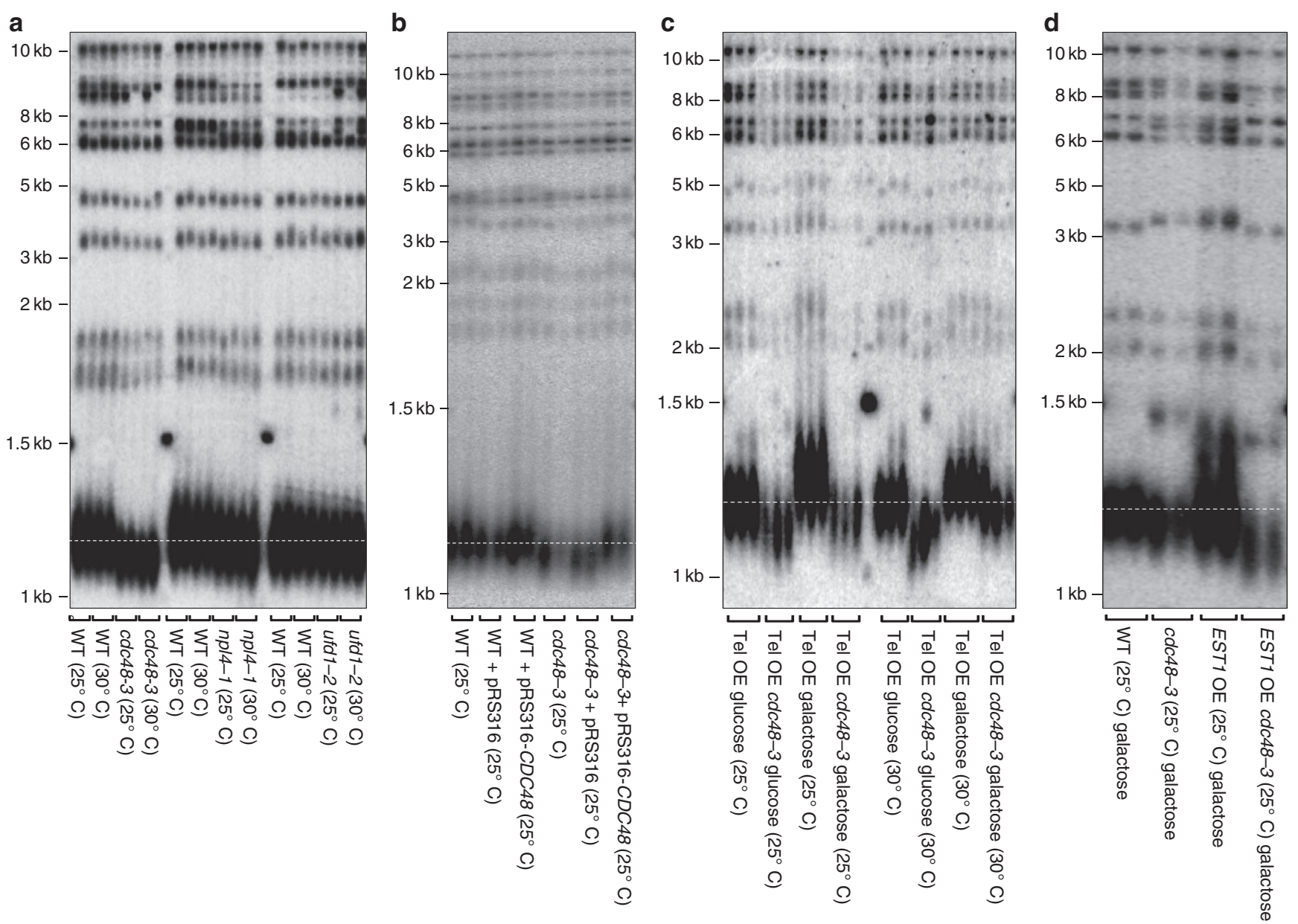

Figure 3 | Telomeres are shorter in cdc48-3 and npl4-1 cells than in WT cells. (a) Southern analysis of DNA from two independent colonies of cdc48-3, npl4-1, and ufd1-2 cells and their respective (WT) isogenic controls was digested with Xhol and analysed by Southern blotting. Temperatures at which cells were grown are indicated. (b) Telomere length of WT or cdc48-3 cells carrying a centromere plasmid with (pRS316-CDC48) or without the CDC48 gene (pRS316) was determined as in a. Symbols are as in a. (c) Southern analysis showed cdc48-3 cells have shorter telomere length in telomerase OE cells, as compared with their WT counterpart, at both permissive and semi-permissive temperatures. Each lane is an independent isolate. (d) Southern analysis of telomere length in Est1 OE cdc48-3 and WT cells.

Est1 is ubiquitinated in $\boldsymbol{c d c 4 8 - 3}$ cells. Est1 is cell cycle regulated $^{19}$ by a process that depends on both the E3 Ub ligase $\mathrm{CDH} 1 / \mathrm{APC}^{50}$ and the proteasome $\mathrm{e}^{20}$, although it is not clear whether either dependency is direct, and ubiquitinated Est1 (Est1-Ub) has not been detected. Our data suggest that when the Cdc48 complex is compromised, Estl will be ubiquitinated but not degraded, leading to the accumulation of Est1-Ub. To test this model, we asked whether Est1-Ub is present in WT and $c d c 48-3$ cells by expressing Myc-tagged Est1 and $\mathrm{His}_{6}$-tagged ubiquitin under the control of the copper-inducible CUP1 promoter in both WT and $c d c 48-3$ cells ${ }^{51}$. Lysates were prepared from log phase cells grown overnight in media containing copper and $\mathrm{His}_{6}$-ubiquitinated proteins were isolated using $\mathrm{Ni}$-conjugated agarose beads (QIAGEN). Eluted proteins were separated by SDS-PAGE and analysed by western blots using anti-Myc (Clontech) to detect Est1 (Fig. 5a and Supplementary Fig. 6A) and anti-His antibodies (Novagen) to detect all ubiquitinated proteins (Supplementary Fig. 6B).

In both copper-treated strains, many proteins were present in the anti-His western blotting, but not in the non-copper-treated controls (Supplementary Fig. 6B, compare lanes 2 and 4 with 1 and 3). Myc-tagged Est1 was among the Ni-affinity isolated proteins from copper-treated cells, indicating that at least a fraction of the Estl was ubiquitinated both in the presence and absence of the Cdc48 complex (Fig. 5a and Supplementary Fig. 6A). Although Est1-Ub was evident in both WT and $c d c 48-3$ cells, it was about 70-80 times more abundant in the latter (Fig. 5a and Supplementary Fig. 6A). After adjusting for Est1 being $~ 40$ times more abundant in $c d c 48-3$ versus WT cells, the fraction of Est 1 that was ubiquitinated was almost twice as high in cdc48-3 compared with WT cells. Although the Cdc48 complex is often described as recognizing polyubiquitinated proteins, in four independent experiments only mono-Ub Est1 was detected. Likewise, a recent paper reports that $\mathrm{Cdc} 48$ complexes in yeast and mammals extract monoubiquitinated transcription factors from $\mathrm{DNA}^{52}$

To determine whether Est1 was ubiquitinated in a cell cycledependent manner, we arrested WT and $c d c 48$ - 3 cells in G1 phase with $\alpha$-factor and G2/M phase with nocodazole, and isolated ubiquitinated proteins from both as in Fig. 5a. In both WT and cdc48-3 cells, levels of mono-Ub Est1 were similar in G1 and G2/ $\mathrm{M}$ phases (Fig. 5b and Supplementary Fig. 6C). Thus, the Cdc48 complex could extract Est1-Ub from telomerase in both G1 and $\mathrm{G} 2 / \mathrm{M}$ phases.

Cell cycle regulation of Est 1 is lost in $c d c 48-3$ cells. Est1 is the only core telomerase subunit whose abundance varies with the 


\section{a}
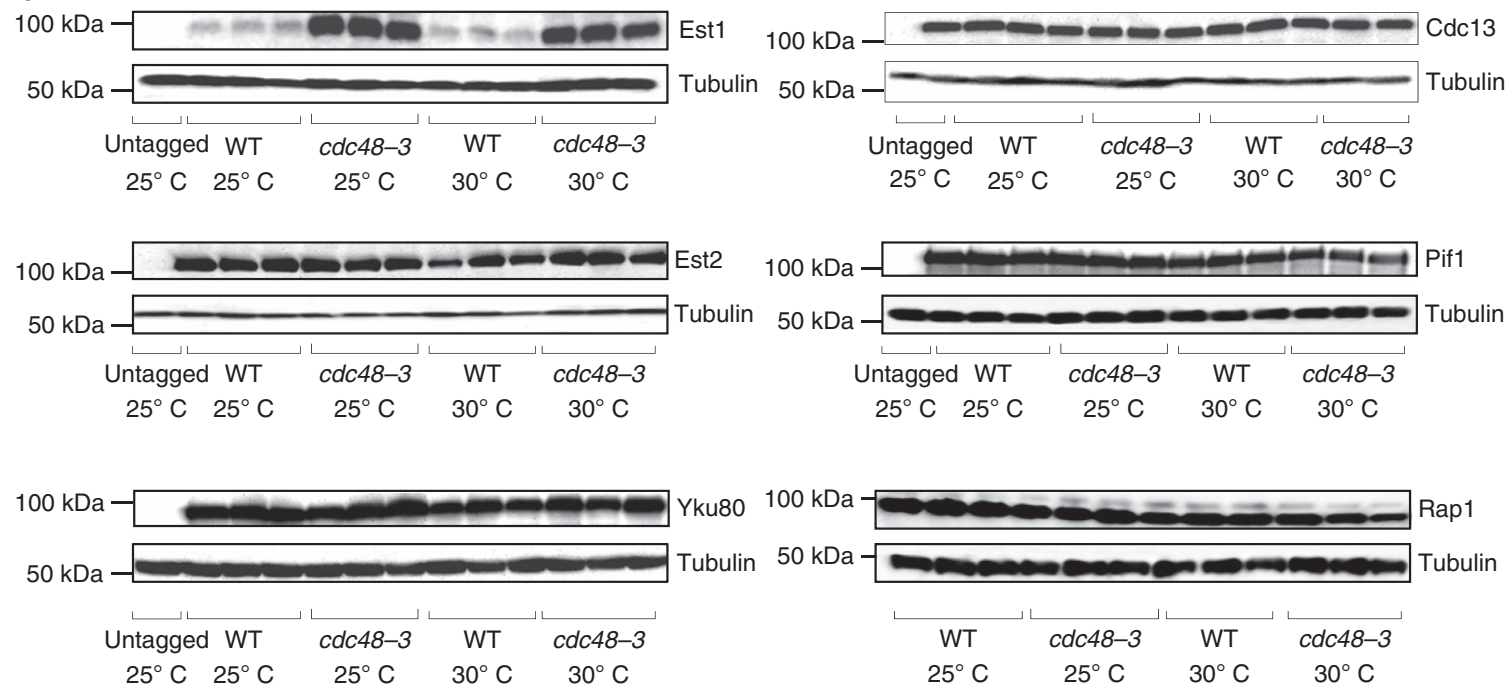

b

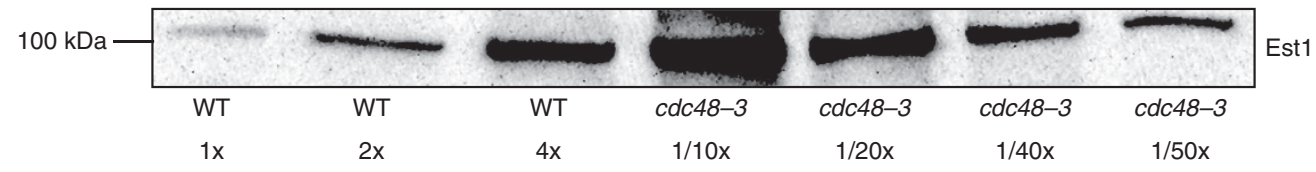

C
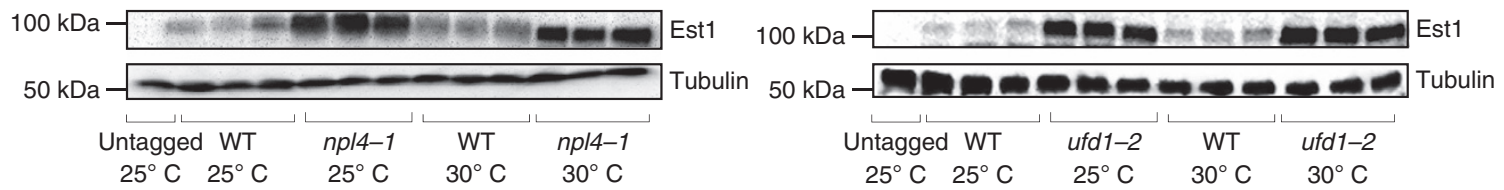

d

\section{IP: anti-Cdc48}

\section{Western: anti-Myc}

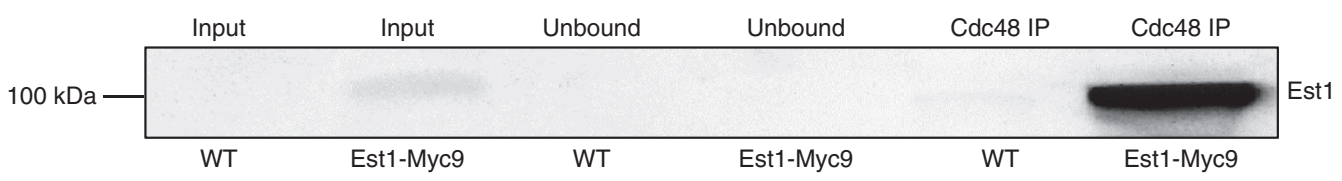

IP: anti-Cdc48

Western: anti-Cdc48

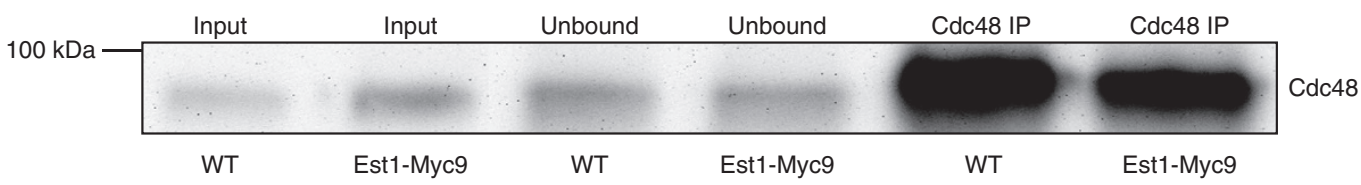

Figure 4 | Est1 physically interacts with Cdc48 and its abundance is increased in cdc48-3, npl4-1 and ufd1-2 cells. (a) Proteins were prepared from three independent isolates of asynchronous cdc $48-3$ cells grown at $25^{\circ} \mathrm{C}$ (permissive temperature) and $30^{\circ} \mathrm{C}$ (semi-permissive temperature) or from otherwise isogenic control cells and subjected to SDS-PAGE and western blot analysis. Est1, Est2, Cdc13, Yku80 and Pif1 were visualized with mouse anti-Myc antibodies (Clontech); Rap1 was visualized with rabbit anti-Rap1 antisera (Conrad et al. ${ }^{48}$ ); $\alpha$-tubulin was visualized with rat anti- $\alpha$-tubulin antibodies (Abcam). (b) Quantification of Est1 levels in WT versus cdc48-3 cells. Extracts were diluted as indicated (or not diluted, $1 \times$ ) and subjected to SDS-PAGE and western blot analysis. Est1 was 40-fold more abundant in cdc48-3 compared with WT cells. (c) Est1 levels were elevated in both np/4-1 and ufd1-2 cells compared with their WT counterparts. Methods are the same as in a. (d) Extract of proteins from untagged WT cells or WT cells expressing Est1-Myc9 (input) was immunoprecipitated with goat anti-Cdc48 polyclonal antibodies (Abgent) (Cdc48 IP) and the samples analysed by western blotting with anti-Myc antibodies (Clontech). Supernatants recovered before and after immunoprecipitation were used as input and unbound controls, respectively (top panel). The same samples were analysed by western blotting using anti-Cdc48 antibodies (Abgent) (bottom panel). See Supplementary Fig. 4 for full lane view of these data.

cell cycle ${ }^{1,8,19}$. Est1 levels are approximately five times higher in G2/M (109 \pm 60.3 molecules per cell; here and elsewhere represents average \pm s.d.) than in G1 phase $(20.3 \pm 11.6)^{1}$. To determine whether the Cdc48 complex is responsible for the cell cycle-regulated abundance of Est1, we arrested WT and $c d c 48-3$ cells in late G1 phase with $\alpha$-factor. We then released cells from 
a

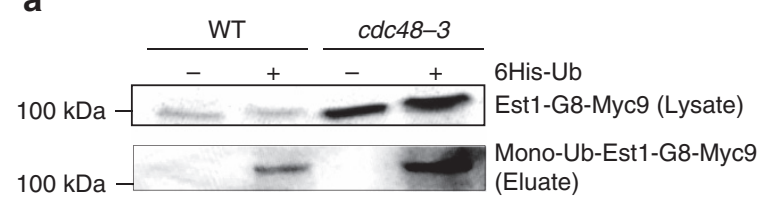

b

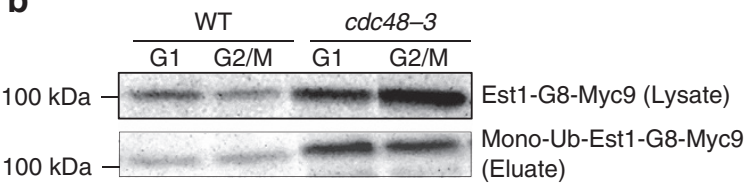

C
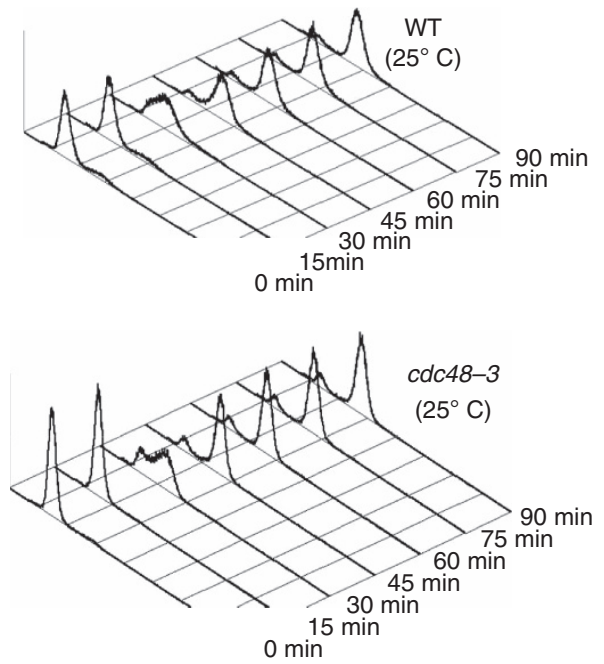

d

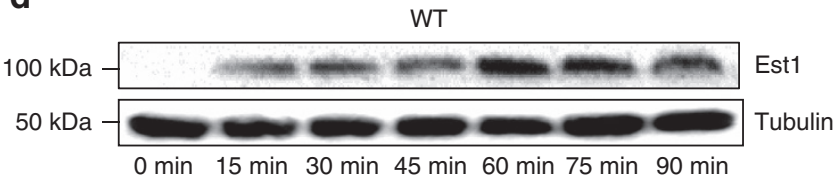

cdc48-3

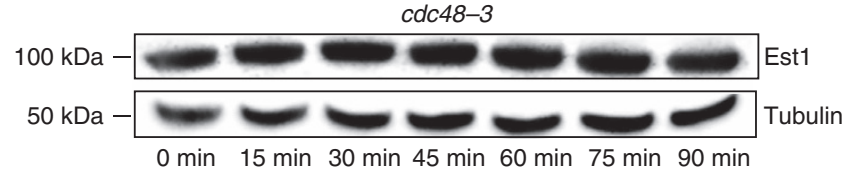

$15 \min 30 \min 45 \min 60 \min 75 \min 90 \mathrm{~min}$ e

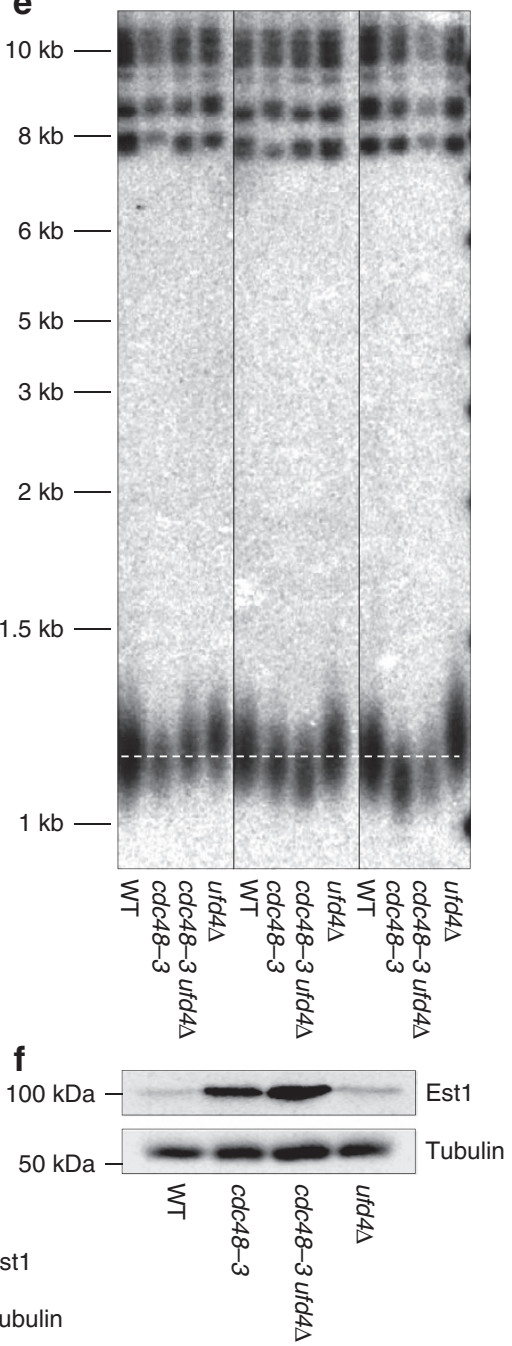

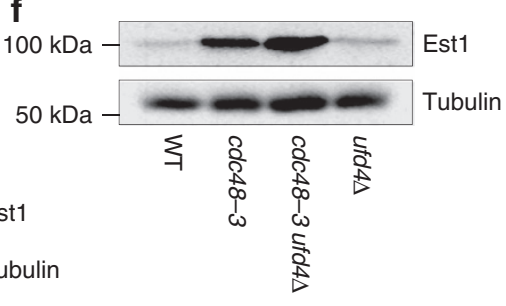

Figure 5 | Ubiquitination of Est1 is increased and cell cycle-regulated abundance of Est1 is lost in cdc48-3 cells. (a) WT and cdc48-3 cells with Est1-G8Myc9 were transformed with a plasmid encoding $6 \mathrm{His}-u b i q u i t i n('+1,6 \mathrm{His}-\mathrm{Ub}$ induction). In both the lysate and eluate, there was $10 \mathrm{X}$ more extract from WT cells than from cdc48-3 cells. Est1 was detected in both strains using anti-Myc western blotting in whole-cell lysates and after elution from Ni-NTA agarose, which purifies ubiquitinated proteins. See Supplementary Fig. 6A for full lane view of these data. (b) Samples were arrested in late G1 phase with $\alpha$-factor (G1) and in G2/M phase with nocodazole (G2/M) and Est1 ubiquitination was detected using western analysis. See Supplementary Fig. 6C for full lane view of these data. (c) FACS profiles of WT (top) and cdc $48-3$ (bottom) cells grown at $25^{\circ} \mathrm{C}$. Cells were arrested in late G1 phase with $\alpha$-factor ( 0 min time point), removed from $\alpha$-factor and allowed to proceed synchronously through the cell cycle. Samples were removed for FACS and western analysis (d) at the indicated time points with anti-Myc. The same membrane was probed with anti- $\alpha$ tubulin as a loading control. See Supplementary Fig. $6 \mathrm{E}$ for full lane view of these data. (e) Southern blot analysis of DNA from three independent colonies of cdc48-3, cdc48-3 ufd $4 \Delta$, ufd $4 \Delta$ cells and their respective (WT) isogenic controls were digested with Xhol and analysed by Southern blotting. (f) Proteins were prepared from $\alpha$-factor-arrested WT, cdc48-3,

cdc48-3 ufd $4 \Delta$ and ufd $4 \Delta$ cells grown at $25^{\circ} \mathrm{C}$ (permissive temperature) and subjected to SDS-PAGE and western analysis of Est 1 with mouse anti-Myc antibodies (Clontech) See Supplementary Fig. 6D for full lane view of these data.

the arrest, allowing them to proceed through a synchronous cell cycle as monitored by fluorescence-activated cell sorting (FACS) (Fig. 5c). As shown previously, in WT cells Est1 was much less abundant in G1 phase than later in the cell cycle (Fig. 5d and Supplementary Fig. 6E). However, in $c d c 48-3$ cells Est1 levels were as high in G1 phase as they were throughout the rest of the cell cycle (Fig. 5d and Supplementary Fig. 6E). Thus, the low level of Est1 in G1 phase is Cdc48 dependent.
Ufd4 affects telomere length and Est1 abundance. Budding yeast encodes $\sim 80 \mathrm{E} 3 \mathrm{Ub}^{\text {ligases }}{ }^{29}$. Because three of these ligases Tom1, Ubr1 and Ufd4 were telomerase associated (Supplementary Data 1), we considered them as candidates for the E3 Ub ligase that modifies Est1. We also considered another E3 Ub ligase, Cdh1, which had been implicated previously in Est1 regulation ${ }^{50}$. We anticipated that deletion of the correct E3 Ub ligase would result in higher levels of Est1 and hence longer 
telomeres in otherwise WT cells. Est1 abundance in $c d c 48-3$ cells lacking the appropriate E3 ligase should be even higher than in cdc48-3 cells alone but the short telomere phenotype of the strain should be suppressed. In two experiments, only ufd $4 \Delta$ had all of the expected phenotypes (Fig. 5e,f and Supplementary Figs 6D and 7). Thus, Ufd4 is probably the E3 Ub ligase that cooperates with the Cdc48 complex to regulate Est1 abundance and degradation.

\section{Discussion}

So far, MS analysis of telomerase has been accomplished only in Tetrahymena cells, as they undergo massive new telomere formation and immortalized human cells, both of which have atypically high levels of telomerase. As yeast telomerase is present in less than one complex per telomere, its isolation is challenging. We (and others) were not successful at purifying telomeraseassociated proteins from budding yeast expressing endogenous levels of telomerase. Statistically robust preparations of telomeraseassociated proteins required telomerase overexpression (Fig. 1d and Supplementary Fig. 1D) and optimized lysis conditions.

Telomerase overexpression had no detectable effects on growth rate or cell cycle progression (Fig. 1b). Moreover, even though telomeres were longer in the $\mathrm{OE}$ strains indicating that the OE telomerase was active, telomeres were not pathologically long as seen in certain mutant backgrounds, such as $c d c 13-5$ or rap $1^{\text {ts }}$ cells $^{53,54}$ (Fig. 1e). The robust association of all known telomerase subunits with the immunoprecipitated complex indicates that the isolated complex is authentic (Supplementary Data 1). Moreover, $\sim 30 \%$ of the telomerase-associated proteins were previously reported to affect telomeres, an enrichment over the $\sim 8 \%$ of yeast genes reported to affect telomere length (Supplementary Data 1).

The telomerase association of $35 \%$ of the 115 proteins, such as the Yku complex, was lost after DNase I treatment (Supplementary Data 1). The Ku complex is telomere associated in yeasts ${ }^{55}$ and mammals ${ }^{56}$. The DNase sensitivity of YKu70/80 and Sir4, another telomere structural protein, probably indicates that their association arises from telomerase that was telomereassociated at the time of cell lysis. However, we do not think these associations necessarily lack biological relevance, as Rap1, the most abundant telomere-binding protein, and the G-tail binding CST complex were not telomerase associated ${ }^{57}$. We speculate that telomerase-binding proteins such as the Yku complex have a particularly close proximity with telomerase when it is telomere bound, thus generating a favourable environment for interaction.

We identified telomerase-associated proteins from both G1 phase, when telomerase is not active, and G2/M phase, when it is. Proteins with roles in protein modification were more abundant in G1 than in G2/M phase telomerase. Degradation of telomerase subunits, such as Est1, or of other positive regulators of the enzyme in G1 phase could explain why telomerase is not active in G1 phase. In contrast, proteins involved in chromatin, silencing, transcription and translation were more highly represented in G2/M phase telomerase, perhaps reflecting a need to remodel telomeric chromatin for telomerase access. Nonetheless, all of the DNAse-resistant, telomerase-associated proteins were present with high specificity in both preparations, perhaps because factors that limit telomerase activity to late S/G2 phase are telomere rather than telomerase-associated. In addition, cell cycle regulation may be influenced in part by posttranslational modifications of telomerase subunits.

Our study identified an unanticipated pathway of telomerase regulation that involves the essential and multifunctional Cdc48Npl4-Ufd1 complex and the E3 Ub ligase Ufd4. All four of these proteins were among the most significant telomerase-associated proteins in our MS analysis (Supplementary Data 1), yet none was linked previously to telomeres. The Cdc48 complex physically interacted with Est1 (Fig. 4d and Supplementary Fig. 4D) and affected its abundance and cell cycle regulation (Figs $4 \mathrm{a}$ and $5 \mathrm{c}, \mathrm{d}$, and Supplementary Figs 4 and 6E). When the abundance of the Cdc48 complex was impaired by temperaturesensitive mutations in any of its three subunits, Est1 levels increased as much as 40-fold (Fig. 4b and Supplementary Fig. 4B), at least a fraction of the accumulated Est1 was monoubiquitinated (Fig. 5a and Supplementary Fig. 6A), and its cell cycle-regulated abundance was lost (Fig. $5 \mathrm{~d}$ and Supplementary Fig. 6E).

Overexpression of Est1 in WT cells results in telomere lengthening $^{49}$ (see also Fig. 3d), consistent with its being a telomerase activator. However, hyper-elongation of telomeres on Est1 overexpression was Cdc48 dependent (Fig. 3d) and $c d c 48-3$ cells had short telomeres (Fig. 3a). These data suggest that Est1$\mathrm{Ub}$ is a less effective telomerase activator than unmodified Est1. If this model is correct, deletion of the E3 Ub ligase responsible for Est1 ubiquitination should result in more Est1 and long telomeres. Indeed, deletion of the telomerase-associated E3 Ub ligase UFD4 resulted in longer telomeres and more Est1 in WT cells (Fig. 5e,f and Supplementary Fig. 6D). Moreover, deleting UFD4 from $c d c 48-3$ cells increased Est 1 abundance even more but had a positive effect on telomere length, presumably because the fraction of ubiquitinated Est1 was reduced and therefore Est1 was better able to promote telomerase activity.

Why is it important to limit holoenzyme assembly to a small window in the cell cycle? A cell cycle-regulated holoenzyme is probably not important for telomere length control, because when the holoenzyme is assembled prematurely in G1 phase, it does not lengthen telomeres ${ }^{20}$. However, double-strand breaks can occur anytime in the cell cycle and their repair by telomere addition, which results in loss of all sequences distal to the site of the break, is a much less favourable outcome than repair by homologous or even non-homologous recombination. In the absence of the Cdc48 complex, Est1 was more abundant and no longer cell cycle regulated (Fig. 5c,d and Supplementary Fig. 6E). Based on these data, we propose that the Cdc48 complex is part of a regulatory circuit that prevents premature assembly of the telomerase holoenzyme in G1 and early $S$ phase (Fig. 6). However, the Cdc48 complex was also abundantly associated with telomerase in G2/M phase and Est1 was ubiquitinated to similar extents in $\mathrm{G} 1$ and $\mathrm{G} 2 / \mathrm{M}$ phase (Fig. $5 \mathrm{~b}$ and Supplementary Fig. 6C), suggesting that the complex may also function to disassemble the holoenzyme at the end of the cell cycle (Supplementary Data 1). Such an activity would be similar to the role of Cdc48-Npl4-Ufd1 in disassembling the replisome at the end of $S$ phase $e^{58,59}$. Moreover, in genetic backgrounds that allow the precocious assembly of the replisome in $\mathrm{G} 1$ phase, the Cdc48 complex can also disassemble it at this time ${ }^{58}$. Thus, there is precedent for proposing that the $\mathrm{Cdc} 48$ complex can prevent telomerase holoenzyme formation in G1 phase and promote its disassembly at the end of the cell cycle.

In carrying out its diverse functions, the Cdc48 complex acts on its substrates when they are bound to a subcellular structure, such as the endoplasmic reticulum or chromatin ${ }^{58,59}$. This property in combination with our model provides an explanation for an otherwise puzzling aspect of telomere biology, the telomere bound but unengaged association of the catalytic core of telomerase, Est 2 and TLC1, in G1 phase when telomerase is not active ${ }^{19}$. We speculate that the transient chromatin association of a precociously assembled telomerase holoenzyme is required to make it a substrate for $\mathrm{Cdc} 48$ mediated disassembly. 
Wild-type cells
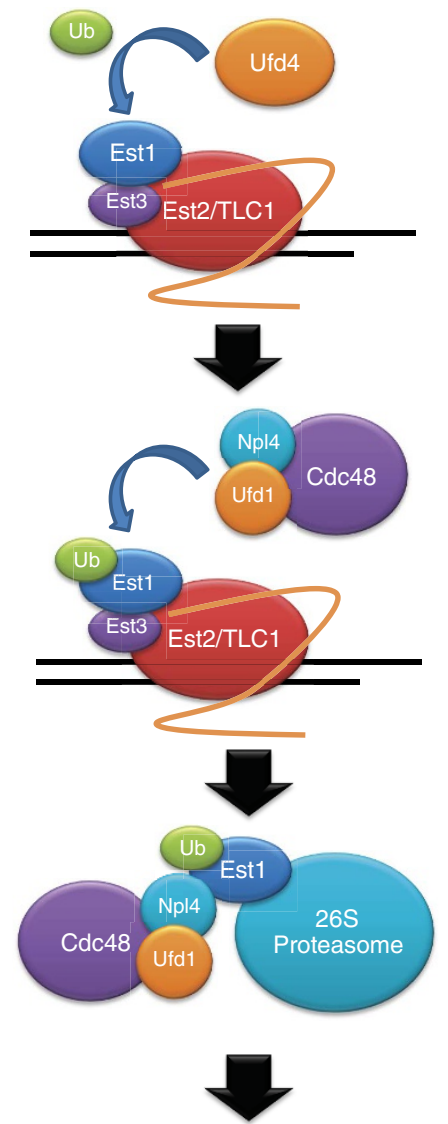

Est1 is extracted in both $\mathrm{G} 1$ and post $\mathrm{S}$ phase Reduced telomere lengthening

Figure 6 | Model for Cdc48-Npl4-Ufd1 regulation of telomerase activity and telomere length. The $\mathrm{Cdc} 48$ complex delivers proteins to the proteasome for degradation and Est1 abundance is cell cycle regulated by a proteasome-dependent process. We show that the $\mathrm{Cdc} 48$ complex is telomerase associated. We propose that Est 1 is ubiquitinated by Ufd 4 and this modified form is less capable than unmodified Est1 at fulfilling the activation function of Est1. The Ub binding subunits of the $\mathrm{Cdc} 48$ complex recognize and bind Est1-Ub, while Cdc48 catalyses its removal from telomerase, thereby rendering telomerase inactive. We propose that removal can occur in $\mathrm{G} 1$ phase to prevent premature assembly of telomerase or in $\mathrm{G} 2 / \mathrm{M}$ phase to promote telomerase disassembly. The $\mathrm{Cd} 48$ complex brings Est1-Ub to the $26 \mathrm{~S}$ proteasome, thereby reducing its abundance.

In summary, we propose that the Cdc48 complex prevents premature assembly of the telomerase holoenzyme early in the cell cycle and promotes its regulated disassembly at the end of the cell cycle. These actions would narrow the cell cycle window in which de novo telomere addition can occur. Given the conserved functions of the Cdc48 complex in DNA repair and replication, its role in telomerase regulation may also be conserved.

\section{Methods}

S. cerevisiae growth conditions and strains. All experiments were performed in the W303 background (RAD5 leu2-3,112 trp1-1 can1-100 ura3-1 ade2-1 his3$11,15)$. Genotypes of the yeast strains used in this study are listed in Supplementary Table 1. Telomerase was prepared for MS analyses from a strain in which Est1, Est2, Est 3 and Tlc1 were OE from the GAL1 promoter at their endogenous loci and as the only copies of the genes in the cell. Telomerase OE strains were cultured in $2 \%$ galactose, because they senesce on glucose medium. In addition, Est1 and Est2 were expressed as GFP fusion proteins: the amino-terminal GFP tag was separated from EST1 or 2 by a five-glycine linker, which increases the functionality of epitope-tagged $S$. cerevisiae proteins ${ }^{60}$. The gene encoding the Barl protease was deleted by insertion of the NatMX cassette ${ }^{61}$. A bar 1: NatMX strain expressing GFP fused to a nuclear localization signal (NLS) from SV40 T antigen at the URA3 locus (ura3::GAL-GFP-NLS) and expressed from the GAL1 promoter was used in parallel experiments to assess nonspecific interactions with the GFP tag.

Cell cycle arrest and FACS analysis were carried out ${ }^{19}$. Briefly, the cells were cultured in YEP-rich media to $\mathrm{OD}_{660} \sim 0.15$ and transferred to media containing $20 \mathrm{ng} \mathrm{ml}^{-1} \alpha$-factor (Sigma) or $15 \mu \mathrm{g} \mathrm{ml}^{-1}$ nocodazole (Sigma-Aldrich) for $4 \mathrm{~h}$ at $30^{\circ} \mathrm{C}$ (or for $6 \mathrm{~h}$ at $25^{\circ} \mathrm{C}$ for temperature-sensitive strains) for arrest at G1 ( $\alpha$-factor) or G2/M phase (nocodazole). Cell cycle position was verified by FACS analyses.

Immuno-affinity purification of telomerase. For MS experiments, two litres of cells were grown to mid-log phase $\left(\mathrm{OD}_{660}=0.5\right)$ in YEP + galactose and were harvested by centrifugation at $4{ }^{\circ} \mathrm{C}$ for $10 \mathrm{~min}$ at $6,118 \mathrm{~g}$. Cell pellets were resuspended in freezing buffer (20 mM Na-HEPES, $1.2 \%$ polyvinylpyrrolidone $(\mathrm{W} / \mathrm{V}), \mathrm{pH} 7.4)$ containing $1 \times$ protease inhibitor cocktail $\left(0.02 \mathrm{mg} \mathrm{ml}^{-1}\right.$ pancreas extract, $0.05 \mathrm{mg} \mathrm{ml}^{-1}$ pronase, $0.005 \mathrm{mg} \mathrm{ml}^{-1}$ thermolysin, $0.0015 \mathrm{mg} \mathrm{ml}^{-1}$ chymotrypsin, $0.33 \mathrm{mg} \mathrm{ml}^{-1}$ papain; Roche) and were frozen dropwise in liquid nitrogen ${ }^{62}$. The frozen cell pellets were cryogenically ground using a Retsch MM301 Mixer Mill (15 cycles $\times 2.5 \mathrm{~min}$ at $30 \mathrm{~Hz}$; Retsch, Newton, PA), to achieve a minimum of $85 \%$ cell lysis, as assessed using light microscopy. Approximately $12 \mathrm{~g}$ of frozen cell powder were resuspended in lysis buffer $(100 \mathrm{mM}$ Hepes $\mathrm{KOH}, \mathrm{pH} 7.9,300 \mathrm{mM}$ potassium acetate, $10 \mathrm{mM}$ magnesium acetate, $10 \%$ glycerol, $0.1 \%$ NP-40, $2 \mathrm{mM}$ EDTA, $2 \mathrm{mM}$-glycerophosphate, $50 \mathrm{mM} \mathrm{NaF}, 1 \mathrm{mM}$ dithiothreitol, $1 \times$ protease inhibitor cocktail (Roche) $)^{63}$ in a ratio of $5 \mathrm{ml}$ of lysis buffer per $1 \mathrm{~g}$ of cells. Cell lysates were homogenized using a PT 10-35 Polytron (Kinematica) for three cycles of $10 \mathrm{~s}$ each, with a 1-min ice incubation between each set. Insoluble material was removed by centrifugation at $4^{\circ} \mathrm{C}$ for $10 \mathrm{~min}$ at $10,876 \mathrm{~g}$. The supernatant was incubated for $30 \mathrm{~min}$ at $4{ }^{\circ} \mathrm{C}$ with $\sim 20 \mathrm{mg}$ of M-270 epoxy magnetic beads (Life Technologies) conjugated with $50 \mu \mathrm{g}$ of in-house-purified polyclonal rabbit anti-GFP antibodies ${ }^{44,64}$. Following incubation, the beads were separated from the solution on a magnet and were washed six times with $1 \mathrm{ml}$ cold lysis buffer. Proteins were eluted from the beads in $40 \mu \mathrm{l}$ of $1 \times$ LDS sample buffer (Life Technologies) and incubated with agitation for $10 \mathrm{~min}$ at room temperature, followed by incubation for $10 \mathrm{~min}$ at $70^{\circ} \mathrm{C}$. Eluted proteins were alkylated with $50 \mathrm{mM}$ iodoacetamide for $30 \mathrm{~min}$ at room temperature in the dark.

The isolated protein complexes were separated on a $4 \%-12 \%$ bis-Tris NuPAGE precast gradient gel (Life Technologies), to reduce sample complexity, and stained with SimpleBlue Coomassie (Life Technologies) for visualization of proteins. Samples were prepared for in-gel digestion by excising gel bands as $1-\mathrm{mm}$ sections. Gel sections from a single immuno-isolation were pooled into approximately ten equal fractions and placed into individual wells of a 96-well plate. The gel pieces were destained in $50 \mathrm{mM}$ ammonium bicarbonate $(\mathrm{ABC}), 50 \%$ acetonitrile (ACN) at room temperature with gentle shaking for $15 \mathrm{~min}$. Next, the samples underwent two rounds of dehydration in $100 \% \mathrm{ACN}$ and rehydration in $50 \mathrm{mM} \mathrm{ABC}$. After a final, third dehydration step in $100 \% \mathrm{ACN}$, the gel pieces were resuspended in a solution of $50 \mathrm{mM} \mathrm{ABC}$ and $12.5 \mathrm{ng}^{-1}$ sequencing grade modified trypsin (Promega) for overnight digestion at $37^{\circ} \mathrm{C}$. Peptides were extracted from the gel pieces in $0.5 \%$ formic acid (FA) at room temperature with gentle shaking for $4 \mathrm{~h}$, followed by a second extraction in $0.5 \% \mathrm{FA} / 50 \% \mathrm{ACN}$ at room temperature with gentle shaking for $2 \mathrm{~h}$. The peptides were concentrated by vacuum centrifugation and acidified with $1 \%$ FA before a final volume of $9 \mu$ for MS analysis.

To determine whether the observed protein interactions were or were not dependent on an association with DNA, the experiments were repeated by comparing cells treated $\left(10 \mu \mathrm{g} \mathrm{ml}^{-1}\right.$ for $\left.30 \mathrm{~min}\right)$ or not treated with DNase I (Sigma-Aldrich). The experimental workflow was the same as above, except the starting material for each isolation was 1 litre of cells. This comparison allowed us to determine which interactions were likely mediated by association with DNA. In some cases, proteins that passed our specificity criteria (described below) in the initial large-scale experiment using 21 of cells were not identified in the smaller scale experiment ( 1 litre cells). These experiments are labelled as 'DNA-dependency inconclusive' (Fig. 2a and Supplementary Data 1).

Mass spectrometry. Before direct infusion, samples were desalted using StageTips and an Empore C18 filter $(3 \mathrm{M})^{65}$ and MS analyses were performed ${ }^{66}$. Briefly, tryptic peptides were separated and analysed by nanoscale liquid chromatography electrospray ionization tandem MS (MS/MS) on a Dionex Ultimate 3000 RSLC system (Dionex Corporation) (running mobile phases: A (aqueous), $0.1 \% \mathrm{FA} / \mathrm{H}_{2} \mathrm{O}$; $\mathrm{B}$ (organic), $0.1 \% \mathrm{FA} / 97 \% \mathrm{ACN} / 2.9 \% \mathrm{H}_{2} \mathrm{O}$ ) directly coupled to an LTQ-Orbitrap XL (ThermoFisher Scientific) instrument. Samples were separated on a nanocapillary reverse-phase PepMapC18 analytical column $(75 \mu \mathrm{m}$ by $15 \mathrm{~cm}$; particle size $1.8 \mu \mathrm{m}$ ) (Dionex Corporation) with a 90 -min linear gradient $(4 \%-35 \%$ mobile phase B). Mass spectra were acquired over the $\mathrm{m} / \mathrm{z}$ range from 350 to 1,700 $(r=30,000$ at $\mathrm{m} / \mathrm{z} 400)$, with data-dependent selection and fragmentation of the top ten most intense precursor ions by collision-induced dissociation. Precursor ions were selected in the ion trap (isolation width $=2.00 \mathrm{Da}$, normalized collision energy $=30 \%$, activation $q=0.250$, activation time $=30 \mathrm{~ms}$ ). MS $/ \mathrm{MS}$ data searches 
were carried out using the following parameters: precursor mass tolerance $=0.02 \mathrm{Da}$; fragment mass tolerance $=0.5 \mathrm{Da}$.

Data and network analyses. MS/MS spectra from raw files corresponding to single biological samples were extracted using Proteome Discoverer (v.1.3, ThermoFisher Scientific) running the SEQUEST (version 1.20) search engine against a database of S. cerevisiae protein sequences (UniProt-SwissProt, 2010-11) and common contaminant sequences. Spectra were searched against indexed peptide databases generated from both the forward sequences and the reversed, concatenated protein sequences. The search parameters included full enzyme specificity with a maximum of two missed cleavages. Parent and fragment ion mass tolerances were limited to 10 p.p.m. and $0.5 \mathrm{Da}$, respectively. All searches incorporated static modification of cysteine by carbamidomethylation $(+57 \mathrm{Da})$ and variable modifications of methionine by oxidation $(+16 \mathrm{Da})$ of serine, threonine and tyrosine by phosphorylation $(+80 \mathrm{Da})$, and of lysine by acetylation $(+42 \mathrm{Da})$. Percolator in ProteomeDiscoverer and PeptideProphet in Scaffold (v 3.3.1; Proteome Software) were used to calculate probabilities for spectral matches ${ }^{67}$. The X!Tandem (GPM 2010.12.1.1, Beavis Informatics) subset database refinement search was selected to include additional variable modifications: deamidation of asparagine and glutamine $(+1 \mathrm{Da})$, pyro-Glu formation of peptide $\mathrm{N}$-terminal glutamate $(+17 \mathrm{Da})$ and diglycine modification of lysine $(+114.1 \mathrm{Da})$, with the high mass accuracy option enabled.

Scaffold confidence filters were selected to reduce peptide false discovery rates $(<1 \%)$. Unweighted spectrum counts from resulting protein lists were exported and used for subsequent analyses. To determine specificity of interaction, proteins were filtered using the SAINT algorithm. A SAINT specificity filter of 0.8 was selected to retain high confidence interactions. Proteins passing the SAINT $P>0.8$ in either $\alpha$-factor-treated or nocodazole-treated isolations were included in the merged set of proteins for fold-change analyses. Unweighted spectrum counts for individual proteins were normalized to GFP spectrum counts from each isolation and averaged. Fold changes are represented as the $\log _{2}$-transformed ratios of average spectrum count values $\left(G_{1} / G_{2} M\right)$. Protein networks were generated using STRING-db ${ }^{40}$ and Cytoscape ${ }^{41}$, incorporating the built-in Gene Ontology annotation functionality for clustering of protein complexes (Gene Ontology Full: geneontology.org/ontlogy/ gene_ontology_edit.obo; Gene Association File for S. cerevisiae: geneontology.org/ gene-associations/gene_association.sgd.gz, curator: SGD)

Gene Ontology enrichment analyses were performed using the Gene Functional Annotation Tool operating on the DAVID Bioinformatics 6.7 online platform $(\mathrm{NIAID} / \mathrm{NIH})^{44,68}$. Proteins identified in telomerase isolations were uploaded as a single protein list using SGD_ID annotations. Proteins enriched in either G1 isolations were uploaded as a separate protein list. Corresponding GO annotations were searched using the whole $S$. cerevisiae genome as background library. Functional Annotation Clustering was performed using the following parameters: Gene Ontology=GOTERM_BP_FULL, Classification Stringency = Highest). DAVID cluster enrichment scores are expressed as the geometric mean of $P$-values for individual genes within each cluster.

Western blotting. Cells were grown in rich medium to mid-log phase for asynchronous cell growth or to early log phase for cell cycle synchrony. Cells were pelleted, resuspended in $0.1 \mathrm{M} \mathrm{NaOH}$ and pelleted. The whole-cell protein was extracted using protein sample buffer ${ }^{69}$. Protein were separated in $8 \%$ SDS-PAGE gels and transferred to nitrocellulose membrane (Millipore). Membranes were blocked in TBST (10 mM Tris, $150 \mathrm{mM} \mathrm{NaCl}, 0.05 \%$ Tween-20) with 5\% milk. Probes used for western blot analysis included mouse anti-GFP monoclonal serum (Roche, 11814460001, dilution 1:1,000), mouse anti-Myc monoclonal antibodies (Clontech, 631206, dilution 1:500), horseradish peroxidase-conjugated goat antirabbit (Bio-Rad, 1706515, dilution 1:5,000), goat anti-mouse immuno-globulin G polyclonal antibodies (Bio-Rad, 1721011, 1:3,000) and rabbit anti-goat immunoglobulin $G$ polyclonal antibodies (Abcam, 6,741, 1:5,000). The full lane view of the these data are shown in the Supplementary Figs.

Co-immunoprecipitation of Cdc48. Cells were grown asynchronously in rich medium to mid-log phase. Extracts were prepared by the glass-bead lysis in TMG-50 (10 mM Tris-HCl, pH 8.0, 1 mM MgCl2, 10\% (v/v) glycerol, $50 \mathrm{mM} \mathrm{NaCl}$, $0.1 \mathrm{mM}$ dithiothreitol, $0.1 \mathrm{mM}$ EDTA, Complete Mini EDTA-free protease inhibitor (Roche)). Total protein was adjusted to $0.5 \%(\mathrm{v} / \mathrm{v})$ Tween-20 and $200 \mathrm{U} \mathrm{ml}^{-1}$ of RNasin (Promega) and SuperRNasin (Ambion) and incubated overnight with goat polyclonal anti-Cdc 48 antibodies (Abgent) at $4{ }^{\circ} \mathrm{C}$. Dynabeads Protein G (Life Technologies) equilibrated with TMG-50 with $0.5 \%$ (v/v) Tween-20 were added and incubated for $4 \mathrm{~h}$ at $4{ }^{\circ} \mathrm{C}$. Beads were washed three times with TMG-50 with $0.5 \%(\mathrm{v} / \mathrm{v})$ Tween-20, and once with TMG-50. The co-immunoprecipitated samples were resuspended in TMG-50 and protein was extracted using protein sample buffer.

Southern blotting. Genomic DNA was isolated from cells using a MasterPure Yeast DNA Isolation kit (Epicentre Biotechnologies), genomic DNA was digested with XhoI, separated on $0.8 \%$ agarose gels, transferred to Hybond $\mathrm{N}+$ nylon membrane (GE Healthcare) and hybridized with a randomly primed ${ }^{32} \mathrm{P}$-labelled telomere probe isolated from pCT300 (ref. 70).
Telomere position effect. TPE was assessed in strains having URA3 adjacent to the left telomere of chromosome VII (ref. 47). Cells growing in YEP $+2 \%$ glucose (or $2 \%$ galactose for OE strains) were diluted to a concentration of $2 \times 10^{7}$ cells per ml Then, tenfold serial dilutions of the cell suspensions were made and $3 \mu \mathrm{l}$ of each dilution was spotted onto synthetic complete (YC) plates, YC plates without uracil (YC-ura) and YC plates containing 0.1\% 5-FOA (Toronto Research Chemical) $\left(\mathrm{YC}+5\right.$-FOA). The plates were incubated at $25^{\circ} \mathrm{C}$ for 3 days.

Purification of ubiquitinated proteins. Cells were transformed with a plasmid (YEp352-6HisUb) harbouring 6His-tagged ubiquitin under the CUP1-inducible promoter ${ }^{51}$. The cells were grown in media lacking uracil (to select for the plasmid). $6 \mathrm{His}$-Ubiquitin was induced by $24 \mathrm{~h}$ treatment with $0.1 \mathrm{mM} \mathrm{CuSO}_{4}$. Cells were harvested and lysed with guanidinium lysis buffer $(6 \mathrm{M}$ guanidine hydrochloride, $100 \mathrm{mM}$ sodium phosphate buffer $\mathrm{pH} 8.0,10 \mathrm{mM}$ Tris- $\mathrm{HCl} \mathrm{pH} 8.0$ $10 \mathrm{mM}$ imidazole, $10 \mathrm{mM} \beta$-mercaptoethanol, $0.1 \%$ Triton X-100, $2.5 \mathrm{mg} \mathrm{ml}^{-1}$ $\mathrm{N}$-methyl maleimide, $0.1 \mathrm{mM}$ MG-132, $1 \times$ protease inhibitor). Purification of 6 His-ubiquitinated proteins was performed using the Ni-NTA $\left(\mathrm{Ni}^{2+}\right.$ nitrilotriacetic acid) agarose beads (QIAGEN). The beads were washed with urea buffer ( $8 \mathrm{M}$ urea, $100 \mathrm{mM}$ sodium phosphate buffer $\mathrm{pH} 6.4$, Tris- $\mathrm{HCl} \mathrm{pH} 6.4$, $10 \mathrm{mM}$ imidazole, $10 \mathrm{mM} \beta$-mercaptoethanol, $0.1 \%$ Triton $\mathrm{X}-100)$ and subsequently eluted with protein sample buffer. Eluted protein samples were separated by SDS-PAGE and analysed by western blots using anti-Myc (Clontech) and anti-His antibodies (Novagen).

\section{References}

1. Wu, Y. \& Zakian, V. A. The telomeric Cdc13 protein interacts directly with the telomerase subunit Estl to bring it to telomeric DNA ends in vitro. Proc. Natl Acad. Sci. USA 108, 20362-20369 (2011).

2. Webb, C. J. \& Zakian, V. A. Schizosaccharomyces pombe Ccq1 and TER1 bind the 14-3-3-like domain of Est1, which promotes and stabilizes telomerasetelomere association. Genes Dev. 26, 82-91 (2012).

3. Singh, S. M. \& Lue, N. F. Ever shorter telomere 1 (EST1)-dependent reverse transcription by Candida telomerase in vitro: evidence in support of an activating function. Proc. Natl Acad. Sci. USA 100, 5718-5723 (2003).

4. Lee, J., Mandell, E. K., Tucey, T. M., Morris, D. K. \& Lundblad, V. The Est3 protein associates with yeast telomerase through an OB-fold domain. Nat. Struct. Mol. Biol. 15, 990-997 (2008).

5. Yu, E. Y., Wang, F., Lei, M. \& Lue, N. F. A proposed OB-fold with a protein interaction surface in Candida albicans telomerase protein Est3. Nat. Struct. Mol. Biol. 15, 985-989 (2008).

6. Wang, F. et al. The POT1-TPP1 telomere complex is a telomerase processivity factor. Nature 445, 506-510 (2007).

7. Xin, H. et al. TPP1 is a homologue of ciliate TEBP-beta and interacts with POT1 to recruit telomerase. Nature 445, 559-562 (2007).

8. Tuzon, C. T., Wu, Y., Chan, A. \& Zakian, V. A. The Saccharomyces cerevisiae telomerase subunit Est3 binds telomeres in a cell cycle- and Est1-dependent manner and interacts directly with Est1 in vitro. PLoS Genet. 7, e1002060 (2011).

9. Friedman, K. L., Heit, J. J., Long, D. M. \& Cech, T. R. N-terminal domain of yeast telomerase reverse transcriptase: recruitment of Est3p to the telomerase complex. Mol. Biol. Cell 14, 1-13 (2003).

10. Talley, J. M., DeZwaan, D. C., Maness, L. D., Freeman, B. C. \& Friedman, K. L. Stimulation of yeast telomerase activity by the ever shorter telomere 3 (Est3) subunit is dependent on direct interaction with the catalytic protein Est2. J. Biol. Chem. 286, 26431-26439 (2011).

11. Kim, N. W. et al. Specific association of human telomerase activity with immortal cells and cancer. Science 266, 2011-2015 (1994).

12. Marguerat, S. et al. Quantitative analysis of fission yeast transcriptomes and proteomes in proliferating and quiescent cells. Cell 151, 671-683 (2012).

13. Mozdy, A. D. \& Cech, T. R. Low abundance of telomerase in yeast: implications for telomerase haploinsufficiency. RNA 12, 1721-1737 (2006).

14. Batista, L. F. \& Artandi, S. E. Understanding telomere diseases through analysis of patient-derived iPS cells. Curr. Opin. Genet. Dev. 23, 526-533 (2013).

15. Savage, S. A. Human telomeres and telomere biology disorders. Prog. Mol. Biol. Trans. Sci. 125, 41-66 (2014).

16. Bernardes de Jesus, B. \& Blasco, M. A. Telomerase at the intersection of cancer and aging. Trends Genet. 29, 513-520 (2013).

17. Diede, S. J. \& Gottschling, D. E. Telomerase-mediated telomere addition in vivo requires DNA primase and DNA polymerases alpha and delta. Cell 99, 723-733 (1999).

18. Marcand, S., Brevet, V., Mann, C. \& Gilson, E. Cell cycle restriction of telomere elongation. Curr. Biol. 10, 487-490 (2000).

19. Taggart, A. K., Teng, S. C. \& Zakian, V. A. Estlp as a cell cycle-regulated activator of telomere-bound telomerase. Science 297, 1023-1026 (2002).

20. Osterhage, J. L., Talley, J. M. \& Friedman, K. L. Proteasome-dependent degradation of Estlp regulates the cell cycle-restricted assembly of telomerase in Saccharomyces cerevisiae. Nat. Struct. Mol. Biol. 13, 720-728 (2006). 
21. Wellinger, R. J. \& Zakian, V. A. Everything you ever wanted to know about Saccharomyces cerevisiae telomeres: beginning to end. Genetics 191, 1073-1105 (2012).

22. Liu, N. N., Han, T. X., Du, L. L. \& Zhou, J. Q. A genome-wide screen for Schizosaccharomyces pombe deletion mutants that affect telomere length. Cell Res. 20, 963-965 (2010).

23. Min, B. \& Collins, K. An RPA-related sequence-specific DNA-binding subunit of telomerase holoenzyme is required for elongation processivity and telomere maintenance. Mol. Cell 36, 609-619 (2009).

24. Witkin, K. L. \& Collins, K. Holoenzyme proteins required for the physiological assembly and activity of telomerase. Genes Dev. 18, 1107-1118 (2004).

25. Witkin, K. L., Prathapam, R. \& Collins, K. Positive and negative regulation of Tetrahymena telomerase holoenzyme. Mol. Cell. Biol. 27, 2074-2083 (2007)

26. Fu, D. \& Collins, K. Purification of human telomerase complexes identifies factors involved in telomerase biogenesis and telomere length regulation. Mol. Cell 28, 773-785 (2007).

27. Venteicher, A. S. et al. A human telomerase holoenzyme protein required for Cajal body localization and telomere synthesis. Science 323, 644-648 (2009).

28. Venteicher, A. S., Meng, Z., Mason, P. J., Veenstra, T. D. \& Artandi, S. E. Identification of ATPases pontin and reptin as telomerase components essential for holoenzyme assembly. Cell 132, 945-957 (2008).

29. Finley, D., Ulrich, H. D., Sommer, T. \& Kaiser, P. The ubiquitin-proteasome system of Saccharomyces cerevisiae. Genetics 192, 319-360 (2012).

30. Jentsch, S. \& Rumpf, S. Cdc48 (p97): a "molecular gearbox" in the ubiquitin pathway? Trends Biochem. Sci. 32, 6-11 (2007).

31. Rumpf, S. \& Jentsch, S. Functional division of substrate processing cofactors of the ubiquitin-selective Cdc48 chaperone. Mol. Cell 21, 261-269 (2006).

32. Bar-Nun, S. The role of $\mathrm{p} 97 / \mathrm{Cdc} 48 \mathrm{p}$ in endoplasmic reticulum-associated degradation: from the immune system to yeast. Curr. Top. Microbiol. Immunol. 300, 95-125 (2005)

33. Buchberger, A. Roles of Cdc48 in regulated protein degradation in yeast. Subcell. Biochem. 66, 195-222 (2013).

34. Hitchcock, A. L. et al. The conserved npl4 protein complex mediates proteasome-dependent membrane-bound transcription factor activation. Mol. Biol. Cell 12, 3226-3241 (2001).

35. Hoppe, T. et al. Activation of a membrane-bound transcription factor by regulated ubiquitin/proteasome-dependent processing. Cell 102, 577-586 (2000).

36. Ju, J. S. \& Weihl, C. C. Inclusion body myopathy, Paget's disease of the bone and fronto-temporal dementia: a disorder of autophagy. Hum. Mol. Genet. 19, R38-R45 (2010)

37. Cristea, I. M., Williams, R., Chait, B. T. \& Rout, M. P. Fluorescent proteins as proteomic probes. Mol. Cell. Proteom. 4, 1933-1941 (2005).

38. Choi, H. et al. SAINT: probabilistic scoring of affinity purification-mass spectrometry data. Nat. Methods. 8, 70-73 (2011)

39. Seto, A. G., Zaug, A. J., Sobel, S. G., Wolin, S. L. \& Cech, T. R. Saccharomyces cerevisiae telomerase is an Sm small nuclear ribonucleoprotein particle. Nature 401, 177-180 (1999).

40. Jensen, L. J. et al. STRING 8--a global view on proteins and their functional interactions in 630 organisms. Nucleic Acids Res. 37, D412-D416 (2009).

41. Cline, M. S. et al. Integration of biological networks and gene expression data using Cytoscape. Nat. Protoc. 2, 2366-2382 (2007).

42. Chamberlain, J. R., Lee, Y., Lane, W. S. \& Engelke, D. R. Purification and characterization of the nuclear RNase $\mathrm{P}$ holoenzyme complex reveals extensive subunit overlap with RNase MRP. Genes Dev. 12, 1678-1690 (1998).

43. DeZwaan, D. C., Toogun, O. A., Echtenkamp, F. J. \& Freeman, B. C. The Hsp82 molecular chaperone promotes a switch between unextendable and extendable telomere states. Nat. Struct. Mol. Biol. 16, 711-716 (2009).

44. Huang, da, W., Sherman, B. T. \& Lempicki, R. A. Systematic and integrative analysis of large gene lists using DAVID bioinformatics resources. Nat. Protoc. 4, 44-57 (2009).

45. Hsieh, M. T. \& Chen, R. H. Cdc48 and cofactors Npl4-Ufd1 are important for G1 progression during heat stress by maintaining cell wall integrity in Saccharomyces cerevisiae. PLoS One 6, e18988 (2011).

46. Tran, J. R., Tomsic, L. R. \& Brodsky, J. L. A Cdc48p-associated factor modulates endoplasmic reticulum-associated degradation, cell stress, and ubiquitinated protein homeostasis. J. Biol. Chem. 286, 5744-5755 (2011)

47. Gottschling, D. E., Aparicio, O. M., Billington, B. L. \& Zakian, V. A. Position effect at $S$. cerevisiae telomeres: reversible repression of Pol II transcription. Cell 63, 751-762 (1990)

48. Conrad, M. N., Wright, J. H., Wolf, A. J. \& Zakian, V. A. RAP1 protein interacts with yeast telomeres in vivo: overproduction alters telomere structure and decreases chromosome stability. Cell 63, 739-750 (1990).

49. Zhang, M. L. et al. Yeast telomerase subunit Estlp has guanine quadruplexpromoting activity that is required for telomere elongation. Nat. Struct. Mol. Biol. 17, 202-209 (2010).
50. Ferguson, J. L., Chao, W. C., Lee, E. \& Friedman, K. L. The anaphase promoting complex contributes to the degradation of the $S$. cerevisiae telomerase recruitment subunit Estlp. PLoS ONE 8, e55055 (2013).

51. Ossareh-Nazari, B. et al. Ubiquitylation by the Ltn1 E3 ligase protects $60 \mathrm{~S}$ ribosomes from starvation-induced selective autophagy. J. Cell. Biol. 204, 909-917 (2014)

52. Ndoja, A., Cohen, R. E. \& Yao, T. Ubiquitin signals proteolysis-independent stripping of transcription factors. Mol. Cell 53, 893-903 (2014).

53. Chandra, A., Hughes, T. R., Nugent, C. I. \& Lundblad, V. Cdc13 both positively and negatively regulates telomere replication. Genes Dev. 15, 404-414 (2001).

54. Kyrion, G., Boakye, K. A. \& Lustig, A. J. C-terminal truncation of RAP1 results in the deregulation of telomere size, stability, and function in Saccharomyces cerevisiae. Mol. Cell. Biol. 12, 5159-5173 (1992).

55. Gravel, S., Larrivee, M., Labrecque, P. \& Wellinger, R. J. Yeast Ku as a regulator of chromosomal DNA end structure. Science 280, 741-744 (1998).

56. Chai, W., Ford, L. P., Lenertz, L., Wright, W. E. \& Shay, J. W. Human Ku70/80 associates physically with telomerase through interaction with hTERT. J. Biol. Chem. 277, 47242-47247 (2002).

57. Vodenicharov, M. D. \& Wellinger, R. J. DNA degradation at unprotected telomeres in yeast is regulated by the CDK1 (Cdc28/Clb) cell-cycle kinase. Mol. Cell 24, 127-137 (2006).

58. Maric, M., Maculins, T., De Piccoli, G. \& Labib, K. Cdc48 and a ubiquitin ligase drive disassembly of the CMG helicase at the end of DNA replication. Science 346, 1253596 (2014).

59. Moreno, S. P., Bailey, R., Campion, N., Herron, S. \& Gambus, A. Polyubiquitylation drives replisome disassembly at the termination of DNA replication. Science 346, 477-481 (2014).

60. Sabourin, M., Tuzon, C. T., Fisher, T. S. \& Zakian, V. A. A flexible protein linker improves the function of epitope-tagged proteins in Saccharomyces cerevisiae. Yeast 24, 39-45 (2007).

61. Van Driessche, B., Tafforeau, L., Hentges, P., Carr, A. M. \& Vandenhaute, J. Additional vectors for PCR-based gene tagging in Saccharomyces cerevisiae and Schizosaccharomyces pombe using nourseothricin resistance. Yeast 22, 1061-1068 (2005).

62. Cristea, I. M. \& Chait, B. T. Affinity purification of protein complexes. Cold Spring Harb. Protoc. 2011 pdb prot5611 doi:10.1101/pdb.prot5611 (2011).

63. Gambus, A. et al. GINS maintains association of Cdc45 with MCM in replisome progression complexes at eukaryotic DNA replication forks. Nat. Cell Biol. 8, 358-366 (2006).

64. Cristea, I. M. \& Chait, B. T. Conjugation of magnetic beads for immunopurification of protein complexes. Cold Spring Harb. Protoc. 2011 pdb prot5610 doi:10.1101/pdb.prot5610 (2011).

65. Rappsilber, J., Mann, M. \& Ishihama, Y. Protocol for micro-purification, enrichment, pre-fractionation and storage of peptides for proteomics using StageTips. Nat. Protoc. 2, 1896-1906 (2007).

66. Greco, T. M., Yu, F., Guise, A. J. \& Cristea, I. M. Nuclear import of histone deacetylase 5 by requisite nuclear localization signal phosphorylation. Mol. Cell. Proteom. 10, M110 004317 (2011).

67. Joshi, P. et al. The functional interactome landscape of the human histone deacetylase family. Mol. Syst. Biol. 9, 672 (2013).

68. Huang, da, W., Sherman, B. T. \& Lempicki, R. A. Bioinformatics enrichment tools: paths toward the comprehensive functional analysis of large gene lists. Nucleic Acids Res. 37, 1-13 (2009).

69. Kushnirov, V. V. Rapid and reliable protein extraction from yeast. Yeast 16, 857-860 (2000)

70. Runge, K. W. \& Zakian, V. A. TEL2, an essential gene required for telomere length regulation and telomere position effect in Saccharomyces cerevisiae. Mol. Cell. Biol. 16, 3094-3105 (1996).

\section{Acknowledgements}

We thank Rey-Huei Chen (Academia Sinica, Taiwan) for providing $c d c 48-3, n p l 4-1$ and ufd1-2 strains, and Jeffrey Brodsky (Pittsburgh University) for CDC48 plasmids. We are grateful to Catherine Dargemont, David Toczyski and Xiaolan Zhao for strains and advice for detecting ubiquitin. We thank Carly Lay Geronimo and Preeti Joshi for contributions to some of the experiments, Chris Webb for guidance on the Northern experiments and for helpful comments on the manuscript, and Christina DeCoste for FACS assistance. This work was supported by NIH grants to VAZ (GM43265) and IMC (DA026192, HD073044). K.R.M. was supported by a grant from the New Jersey Commission on Cancer Research and A.J.G. was supported by a National Science Foundation Graduate Research Fellowship.

\section{Author contributions}

K.R.M. began the project. Through considerable trial and error, she constructed and characterized the telomerase OE strain and developed the lysis conditions. K.W.L. designed and carried out almost all of the rest of the experiments. A.J.G. and I.M.C. are responsible for Fig. 2 and Supplementary Fig. 2, and Table 1. A.C. contributed to multiple experiments and is responsible for Figs 1e, 5e, $5 \mathrm{f}$ and Supplementary Fig. 6D 
and 7. I.M.C. helped design and interpret MS data and V.A.Z. did the same for all other experimental data. All of the authors contributed to writing the paper.

\section{Additional information}

Supplementary Information accompanies this paper at http://www.nature.com/ naturecommunications

Competing financial interests: The authors declare no competing financial interest.

Reprints and permission information is available online at http://npg.nature.com/ reprintsandpermissions/
How to cite this article: Lin, K.-W. et al. Proteomics of yeast telomerase identified Cdc48-Npl4-Ufd1 and Ufd4 as regulators of Est1 and telomere length. Nat. Commun. 6:8290 doi: 10.1038/ncomms9290 (2015).

cc (i) This work is licensed under a Creative Commons Attribution 4.0 International License. The images or other third party material In
in this article are included in the article's Creative Commons license, unless indicated otherwise in the credit line; if the material is not included under the Creative Commons license, users will need to obtain permission from the license holder to reproduce the material. To view a copy of this license, visit http://creativecommons.org/ licenses/by/4.0/ 